\title{
Revitalizing the HIV Response in Pakistan
}

\section{A SYSTEMATIC REVIEW AND POLICY RECOMMENDATIONS}

\section{Synthesis Report}

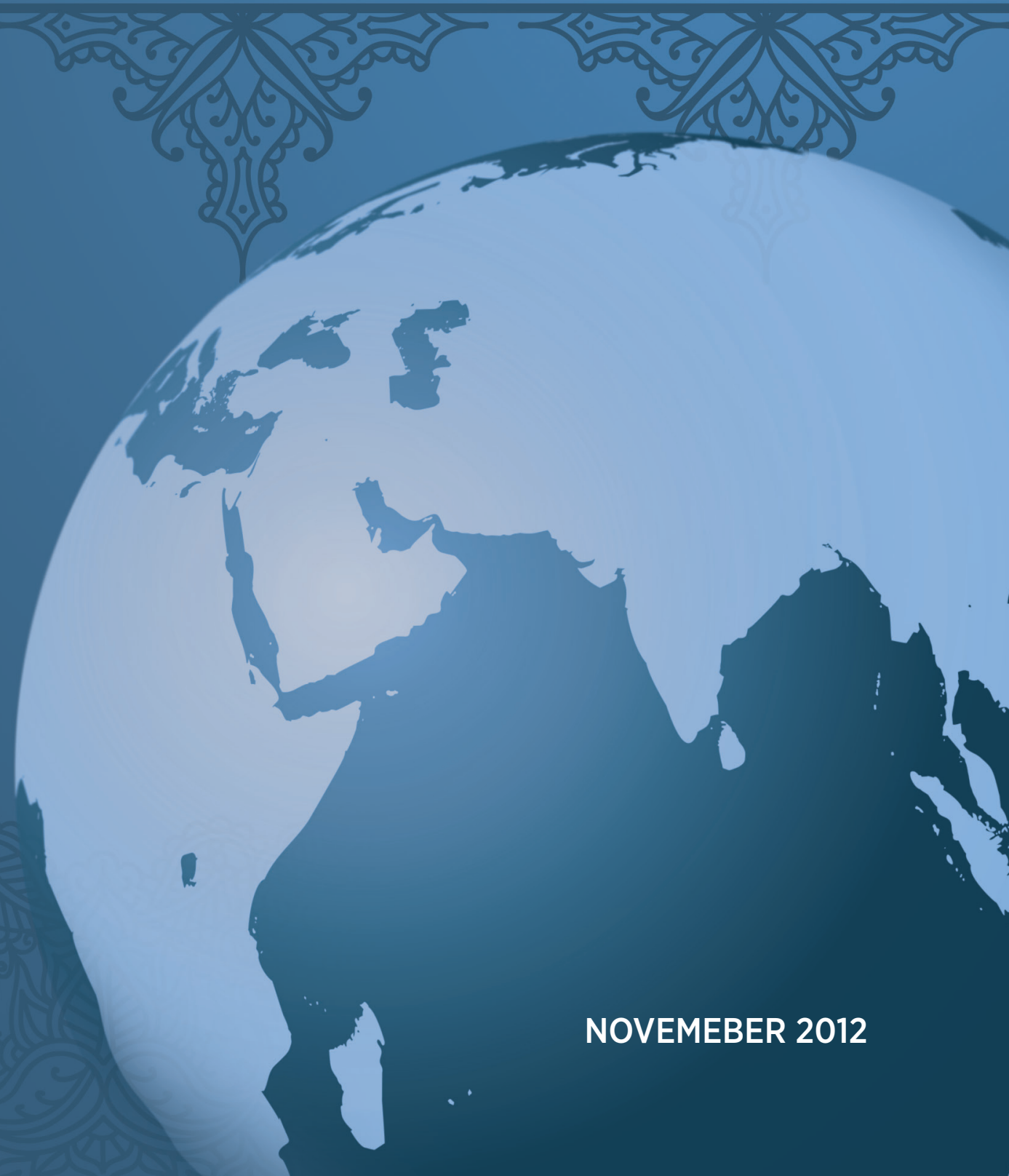




\title{
Revitalizing the HIV Response in Pakistan: A systematic review and policy recommendations
}

\author{
Synthesis Report
}

\author{
Chris Beyrer ${ }^{1}$, Sonal Singh ${ }^{1}$, Marco Ambrosio ${ }^{1}$ \\ Iris Semini ${ }^{2}$
}

Suggested citation:

Beyrer, C., Singh S., Ambrosio M., and Semini I.. Revitalizing the HIV Response in Pakistan: A Systematic Review and Policy Recommendations. The World Bank, 2012.

This work is a product of the staff of The World Bank with external contributions. The findings, interpretations, and conclusions expressed in this work do not necessarily reflect the views of The World Bank, its Board of Executive Directors or the governments they represent.

\footnotetext{
${ }^{1}$ Center for Public Health and Human Rights, Johns Hopkins University

${ }^{2}$ Task Team Leader, Global HIV/AIDS Program, World Bank
} 


\section{Table of Contents}

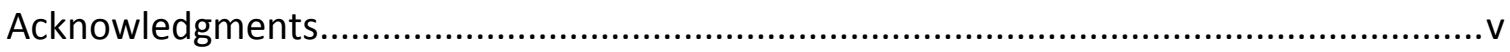

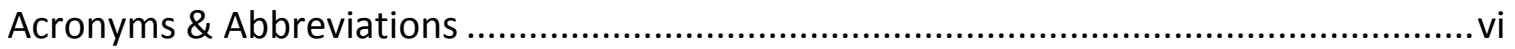

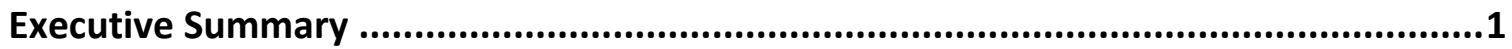

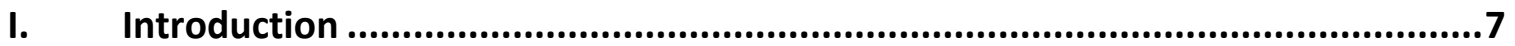

II. Epidemiology Methods..........................................................................

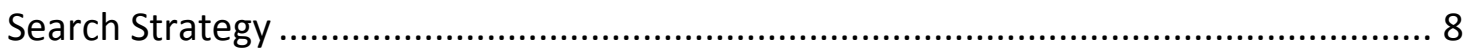

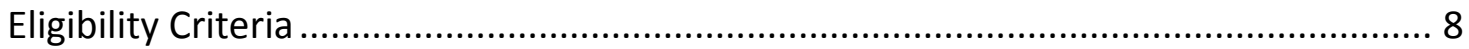

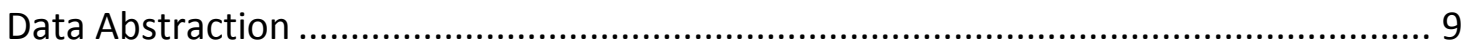

Study Quality or Risk of Bias of Included Studies .................................................... 9

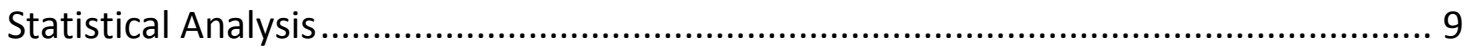

Grading the Strength of Epidemiologic Evidence and Recommendations................. 10

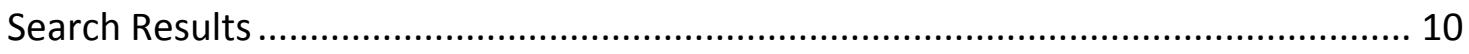

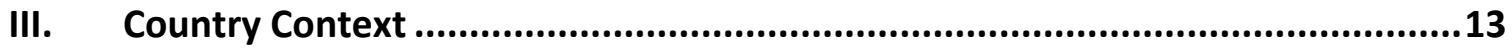

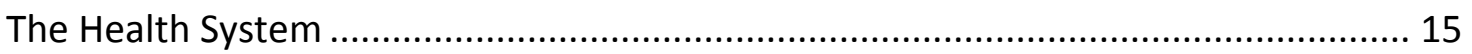

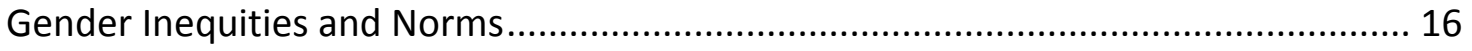

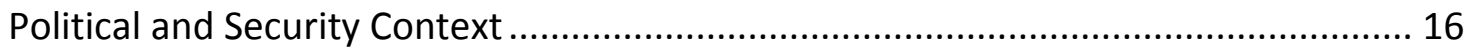

Social and Legal Context for HIV Response ............................................................ 17

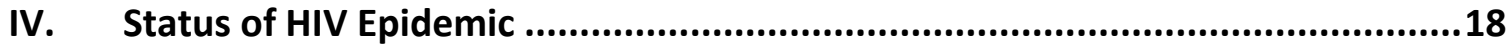

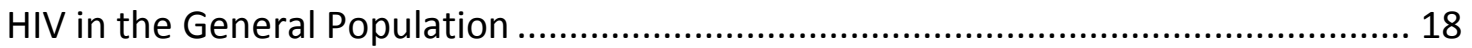

People Living with HIV .................................................................................. 18

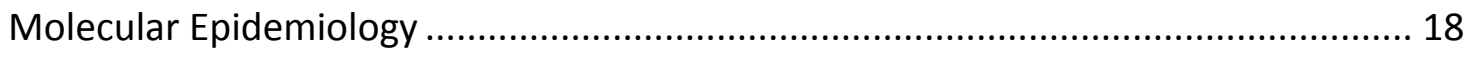

Populations at Greatest Risk .............................................................................. 21

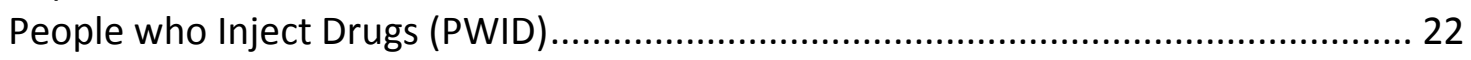

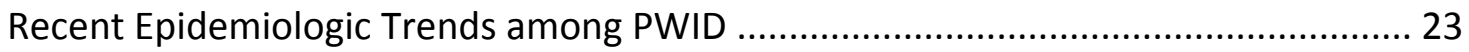

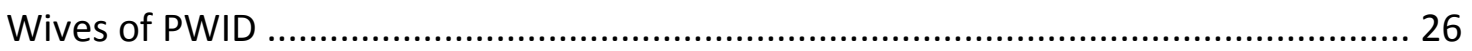

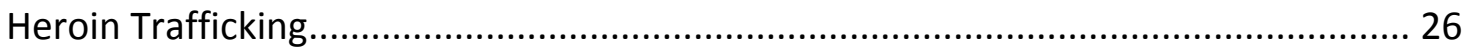

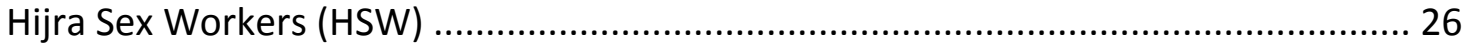

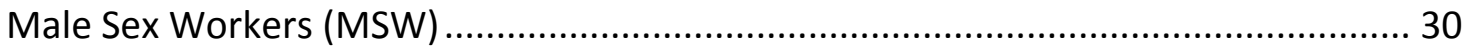

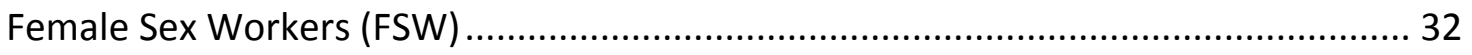

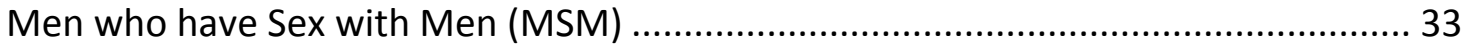

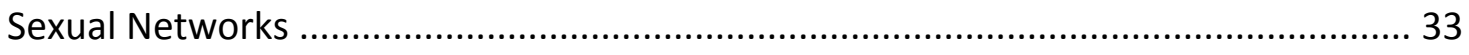

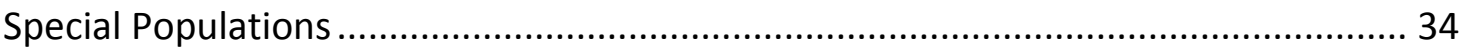

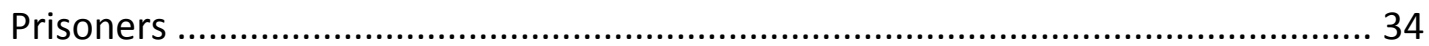

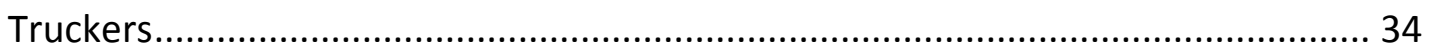

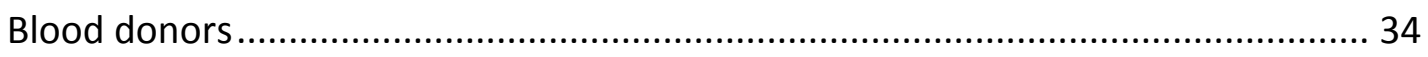

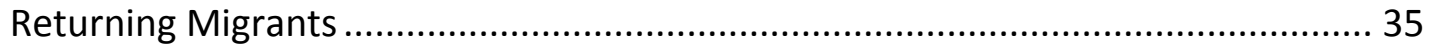

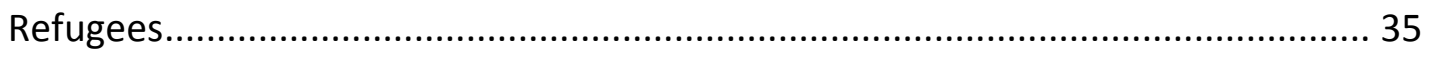

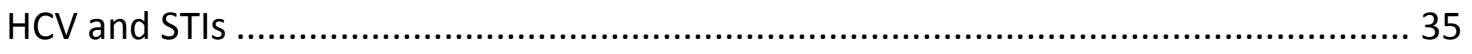

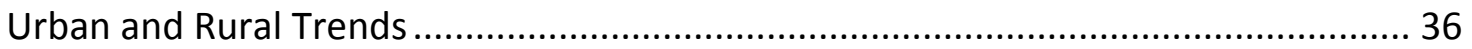

Estimated Number of HIV+ per High-Risk Group by City...................................... 36

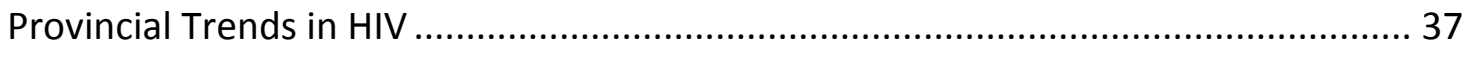

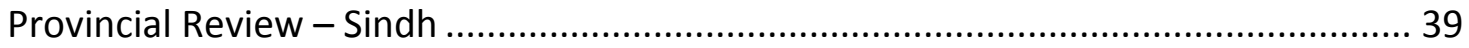




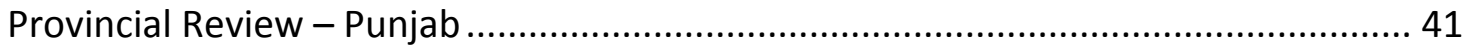

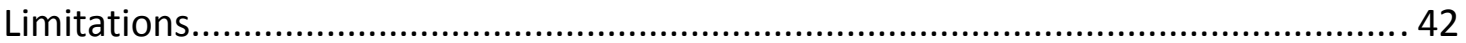

Research Gaps in Surveillance and Programmatic Response .................................. 42

V. Epidemiology - Summary of Key Findings...................................................44

VI. A Systems Response to HIV and AIDS in Pakistan ......................................48

Insufficient Coverage, Intensity and Scale Up of Effective Prevention Interventions.. 48

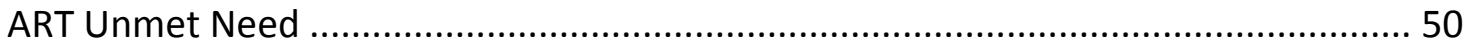

Estimation of High-Risk Groups Requiring Therapy............................................ 51

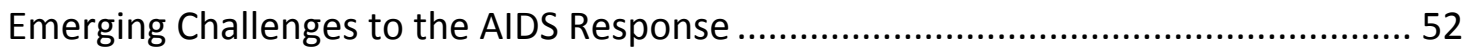

Provincial Deregulation and Implications for HIV Response .................................... 53

VII. Key Policy Recommendations........................................................................55

An Integrated Model for Improved HIV Services Delivery in Pakistan ........................ 55

Outreach and Engagement for those at risk: PWID, HSW, MSW ........................... 57

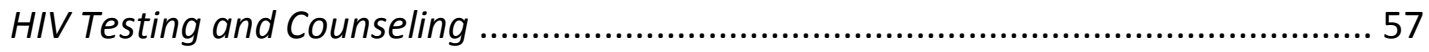

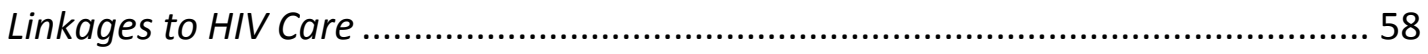

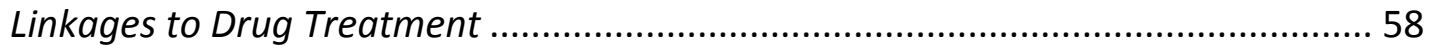

Expanded Targeting and HIV Testing, Linkages to Care, and ARV for Women at Risk. 59

Blood Products Safety and Universal Precautions................................................. 59

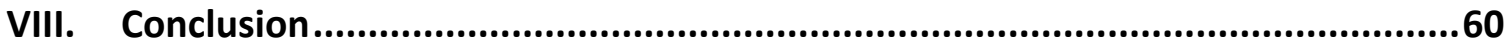

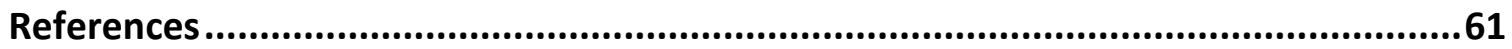




\section{List of Tables}

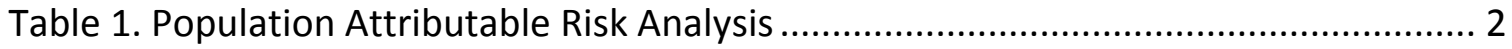

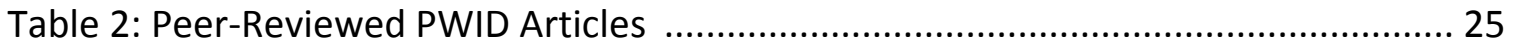

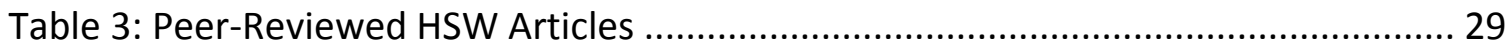

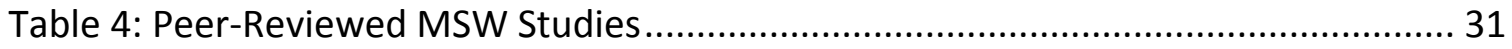

Table 5: Estimated Number of HIV+ per High-Risk Group by City .................................. 37

Table 6: Estimated Size of High-Risk Groups by Province, 2007 .................................... 37

Table 7: HIV Prevalence among PWID (95 percent CI) by City, 2008 ............................. 38

Table 8: Comparison of HIV Prevalence among PWID by City, 2005 and 2008 ............... 38

Table 9: Estimated High-Risk Groups in Sindh, 2007 .................................................. 40

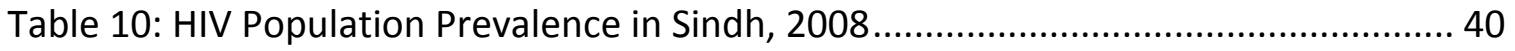

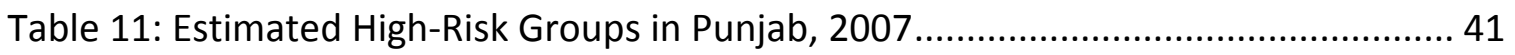

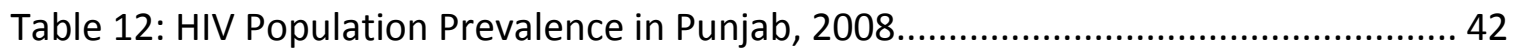

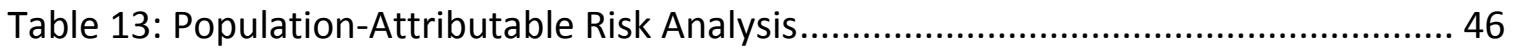

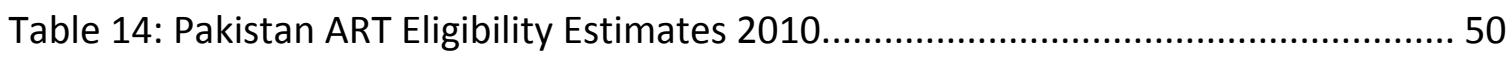

Table 15: Estimated Number of High-Risk Groups Requiring Therapy........................... 52

\section{List of Figures}

Figure 1. Integrated Model for HIV Services Delivery .................................................. 5

Figure 2: PRISMA Flow Sheet for Systematic Review of HIV in Pakistan........................ 12

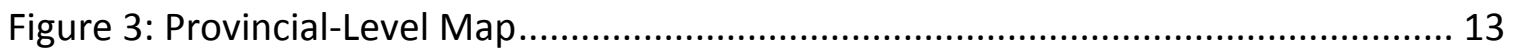

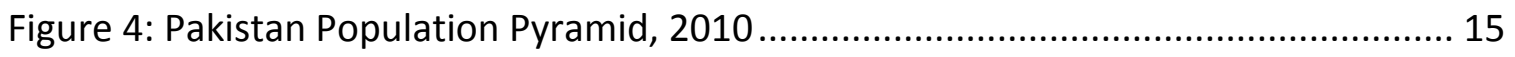

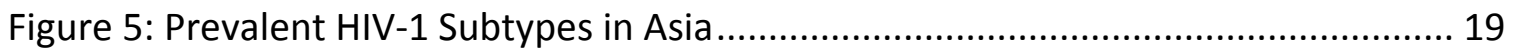

Figure 6: Proportions of PWID, and SW Sub-Groups among At-Risk Populations, 2007 . 20

Figure 7: HIV Prevalence Trends among MARPs, 2005-09 ......................................... 21

Figure 8: National Estimates of HIV Prevalence among PWID in Select Cities, 2008 ....... 23

Figure 9: Proportion of PWID Sharing Syringes/Needles on Last Injection by City, 200839

Figure 10: Integrated Model for HIV Services Delivery ............................................... 56 


\section{Acknowledgments}

This study is a product of collaboration between the World Bank team led by Iris Semini (Task Team Leader) and the Center for Public Health and Human Rights, Johns Hopkins University team: Sonal Singh, Marco Ambrosio, and Andrea Wirtz, led by Chris Beyrer. The authors would like to thank the National AIDS Control Program, Pakistan and the Provincial AIDS Control Programs, Non-Governmental Organizations, bilateral agencies, donors and UN bodies for providing the data. We extend our sincerest thanks to Oussama Tawil and Muhammad Saleem, UNAIDS Country Office in Pakistan, for guidance and input during the review, the analysis and producing the report, as well as for support from this office with the country consultation. We would like to thank Kees Kostermans, Lead Health Specialist at the World Bank, for his comments on the conceptualization of the study and the analysis. We are additionally grateful for comments and input offered by Nicole Fraser-Hurt (Global HIV/AIDS Program, World Bank), as well as for logistic support from Mario Méndez (Global HIV/AIDS Program, World Bank). We gratefully acknowledge the support of Andrea Wirtz, MHS Research Associate at the Center for Public Health and Human Rights, Johns Hopkins Bloomberg School of Public Health, for assistance with tables and figures. 


\section{Acronyms \& Abbreviations}

\begin{tabular}{|c|c|}
\hline ART & Antiretroviral Therapy \\
\hline ARV & Antiretrovirals \\
\hline $\mathrm{BCC}$ & Behavior Change Communication \\
\hline CSW & Commercial Sex Worker \\
\hline FATA & Federally-Administered Tribal Areas \\
\hline FSW & Female Sex Workers \\
\hline HASP & HIV/AIDS Surveillance Project \\
\hline $\mathrm{HCV}$ & Hepatitis C Virus \\
\hline HDI & Human Development Index \\
\hline HRG & High-Risk Group \\
\hline HSW & Hijra Sex Worker \\
\hline HPTN & HIV Prevention Trials Network \\
\hline KPK & Khyber Pakhtunkhwa \\
\hline MARPS & Most-At-Risk Populations \\
\hline MMT & Methadone Maintenance Therapy \\
\hline MOPH & Ministry of Public Health \\
\hline MSW & Male Sex Workers \\
\hline MSM & Men who have Sex with Men \\
\hline NACP & National AIDS Control Program \\
\hline NGO & Non-Governmental Organizations \\
\hline NSEP & Needle and Syringe Exchange Program \\
\hline OST & Opioid Substitution Therapy \\
\hline PLWH & People Living with HIV \\
\hline PMTCT & Prevention of Mother-to-Child Transmission of HIV \\
\hline PWID & People Who Inject Drugs \\
\hline Prov HA & Provincial Health Authority \\
\hline STI & Sexually Transmitted Infection \\
\hline TFR & Total Fertility Rate \\
\hline UN & United Nations \\
\hline UNAIDS & Joint United Nations Programme on HIV/AIDS \\
\hline UNFPA & United Nations Population Fund \\
\hline UNICEF & United Nations Children's Fund \\
\hline UNODC & United Nations Office on Drugs and Crime \\
\hline VCT & Volunteer Counseling and Testing \\
\hline
\end{tabular}




\section{Executive Summary}

This report aims to systematically review and synthesize the current epidemiology of HIV in Pakistan and determine the highest priority actions for evidence based public policy investments aiming to improve the effectiveness and efficiency of the HIV response implementation.

Pakistan has a highly concentrated epidemic of HIV-1, with evidence of high rates of infection among most-at-risk populations but very low general population rates of HIV. Responding to such highly concentrated but low general-population-prevalence HIV epidemics will become increasingly challenging as donor resources decline in settings such as Pakistan.

Pakistan is unlikely to experience a generalized epidemic. After two decades, HIV rates in the general population remain very low, $<1 / 1000$, and the epidemic remains highly concentrated among most-at-risk populations. The latter include people who inject drugs (PWID), who are overwhelmingly male in the studies, and the suggestive emerging epidemic among hijra sex workers (HSW), the wives and sexual partners of HIV-positive PWID, HSWs and their clients, the wives of men who have sex with me (MSM), and female sex workers (FSW) and their sexual partners and clients in urban areas.

In all, it is estimated that some 99 percent of cumulative HIV infections in Pakistan have been among these 5 most-at-risk populations, despite their accounting for well under 2 percent of all adults. PWID accounted for the largest share of infections for any one group, some 36.4 percent overall. Female, male, and transgender sex workers accounted for 24 percent, 12 percent, and 17.5 percent respectively, a cumulative population attributable risk of 53.5 percent of all infections occurring among sex workers. 
Table 1. Population Attributable Risk Analysis

\begin{tabular}{|l|l|l|l|l|l|}
\hline $\begin{array}{l}\text { Risk } \\
\text { group }\end{array}$ & $\begin{array}{l}\text { HIV } \\
\text { Prevalence, \% } \\
*\end{array}$ & $\begin{array}{l}\text { Prevalence } \\
\text { Risk Ratio § }\end{array}$ & $\begin{array}{l}\text { Attributable } \\
\text { Risk, \% }\end{array}$ & $\begin{array}{l}\text { Prevalence of Exposure } \\
\text { in Population, per } \\
1000 \text { adult males** }\end{array}$ & $\begin{array}{l}\text { Population } \\
\text { Attributable } \\
\text { Risk, \% }\end{array}$ \\
\hline PWID & 27.2 & 68 & 98.5 & 3.7 & 36.4 \\
\hline FSW & 0.6 & 1.5 & 33.3 & 7.2 & 24 \\
\hline MSW & 1.6 & 4 & 75 & 1.6 & 12 \\
\hline HSW & 5.2 & 13 & 92.3 & 1.9 & 17.5 \\
\hline MSM & $10.9^{\text {ql }}$ & 27.3 & 96.3 & $1.0^{++}$ & 9.6 \\
\hline
\end{tabular}

* NACP 2012; ** NACP 2012

$\S$ PRR estimated based on baseline risk of HIV in Pakistan $=0.04 \%$ from antenatal surveillance study among pregnant women (NACP 2012)

In Khanani et al 2010 a cross-sectional RDS sample of MSM in Karachi;

++ Data on prevalence of male to male sex behavior unavailable from HASP and extrapolated from a data synthesis of Middle East and North Africa at very conservative estimate of 1/1000, Mumtaz 2010

Note: Attributable risk and population attributable risk may sum up to $>100 \%$ because of shared risk factors.

The high rate of male circumcision (95 percent) in the country almost certainly has played a role in reducing the risk of heterosexual transmission of HIV. Thus, while the data above do suggest a self-sustaining mode of transmission in the most-at-risk populations, the lack of substantial overlap of sexual networks along with the high rates of circumcision in Pakistan suggest that onward transmission to the general population or overlapping sexual networks are likely to be minimal, except in the case of wives and partners of PWID and HSWs. Although high rates of Hepatitis B and Hepatitis C are reported in the blood supply, the overall contribution of this to the burden of the HIV epidemic in Pakistan remains unsubstantiated.

There were substantial variations and heterogeneity from province to province, Sindh and Punjab are the most affected by the HIV epidemic and host the majority of at-risk populations. The epidemic of HIV in Pakistan is concentrated in the major urban cities as consistently seen in multiple studies of reasonable validity although the prevalence rates reported were somewhat imprecise due to sampling uncertainty.

Despite limitations and gaps in surveillance and program monitoring, there was sufficient data to inform an evidence-based response. Given the high rates of HIV among PWID, and the suggestive emerging epidemic among HSWs, the wives of HIVpositive PWID, HSWs and their clients, and the wives of MSM, these Pakistani 
populations are the priority for HIV/STI prevention, treatment, care and support. FSWs remain a priority group given the slight increase of HIV prevalence rates documented in the 2011 Integrated Bio-Behavioral Surveillance (IBBS) (NACP 2012), and the large presence and diversification of typology coupled with heightened marginalization.

While PWID, HSWs, and MSWs are challenging populations to reach, to provide services, and to engage in healthcare generally, the marked concentration of HIV in these few groups, and the overall very low rates in the general population, creates a window of opportunity for a potentially focused, cost-effective, and targeted response strategy. Overall, Pakistan has made strides over the last decade in its AIDS response, with active surveillance, considerable research, both governmental and non-governmental prevention and care activities, and treatment since 2005-06.

Since the first outbreak in Sindh in 2003-04, national and international actors swiftly responded to evidence of the existence of a concentrated epidemic among PWID. HIV prevention interventions have been implemented for FSWs and, to a lesser extent, for MSM and HSWs as well. By the mid-2000s, needle syringe exchange programs (NSEP) were being implemented in large cities and, with an annual budget of around US\$10 million through the "Enhanced AIDS Control Programme" focusing on PWID as well as sex work through World Bank, DFID and government funding (Khan 2011). Harm and risk reduction measures, implemented through provision of "one-stop shop" services targeting key populations, namely PWID, FSWs, HSWs and MSWs, included NSEP, treatment of drug dependence, condoms, prevention and treatment of STIs, primary health care including referral for Hepatitis and Tuberculosis (TB), prevention education through outreach, and peer and social support. Volunteer counseling and testing (VCT) and referral to antiretroviral therapy (ART) were part of the package.

Despite adequate prioritization of the response and resources, PWID, HSWs, MSWs and FSWs face several barriers in terms of access to both prevention and treatment services. HIV prevalence and related behavior indicators suggest lags in implementation. This targeted approach could increase the overall cost effectiveness of the response and ensure a return on investments. By mid-2010, 60 percent of the total AIDS-related resources were allocated for prevention and more than 50 percent of these resources funded harm reduction programs (UNAIDS NASA 2011). Nevertheless, by 2009, only 7 of 22 cities nationwide with populations of over 200,000 had interventions for PWID corresponding to about 30 percent coverage in major cities and about 13 percent nationwide for all urban and rural locations. 
Access to ART and prevention of mother-to-child transmission (PMTCT) remain extremely low. The estimated number of adults (15+) in need of ART in 2010 was 20,000 $(14,000-47,000)$. Given that there are approximately 1,900 people currently on ART, the unmet need for eligible treatment is over 90 percent. This percentage may be underestimated, given the wide confidence interval for the estimated number of adults in need of treatment. The population of persons on antiretrovirals (ARV) is heavily overrepresented by returning migrant workers and their families, and is heavily underrepresented by the two populations with the highest measured HIV infection rates-PWID and hijra, as well as the other two at-risk populations. The number of those most-at-risk requiring highly active antiretroviral therapy (HAART) in Pakistan is estimated to be a manageable number, within the reach of available resources. However, despite the consistent high prevalence of HIV, several barriers prevent PWID and the other at-risk populations from easily accessing both prevention and treatment services. Although national policy has been revised on this, many health care professionals continue to require that HIV-positive PWID be drug-free in order to receive $A R T$, which is a significant barrier for linking HIV-positive PWID to treatment services.

The gains made to date are threatened by internal and external factors. Pakistan has seen a marked decline in external funding and decreasing donor focus on HIV-specific support in 2010-11, which resulted in the disruption of services for PWID and other atrisk populations. The decision to devolve health sector functions to the provincial level creates challenges but it also provides a window of opportunity to reduce dependence on external funding through increasing local allocation to the provincial HIV programs integrated in the provincial health plans and priorities.

This report presents an integrated model for HIV services delivery that depicts a continuum of care from prevention outreach to treatment with a focus on evidencebased interventions and strong linkages. It describes three potential models for VCT services for most-at-risk populations that increase outreach and engagement with PWID, hijra communities, and MSWs and their clients. It also places heavy emphasis on evidence-based approaches to prevention including expanding treatment for HRGs and improving the linkages for HIV+ and HIV- PWID for drug treatment services, such as methadone maintenance therapy (MMT), and outlines the following steps for an evidenced based, effective and efficient policy response at a time of shrinking resources for HIV in overall low prevalence settings. 
Figure 1. Integrated Model for HIV Services Delivery

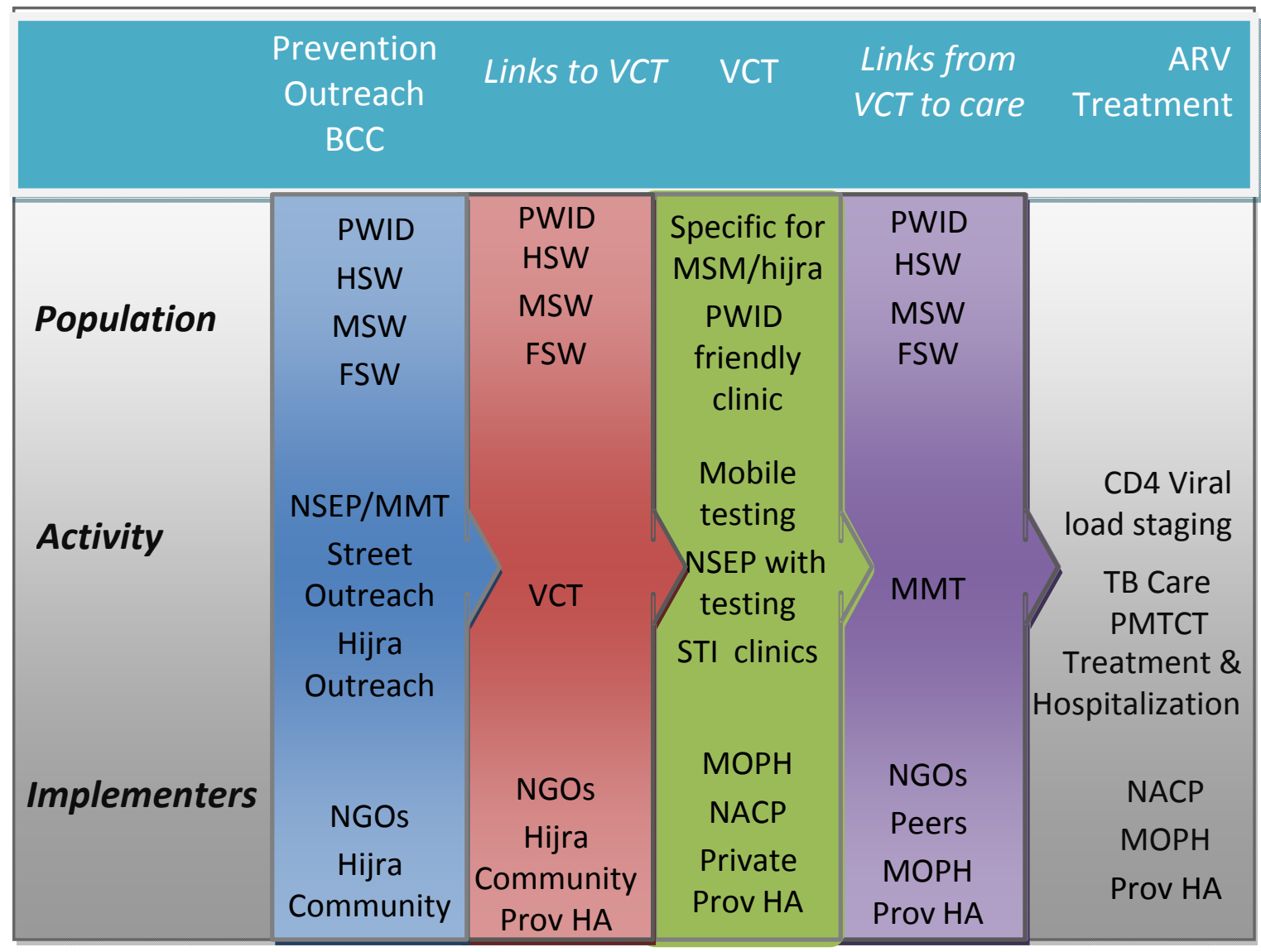

BCC: Behavior Change Communication; MMT: Methadone Maintenance Therapy; NSEP: Needle and Syringe Exchange Program; Prov HA: Provincial Health Authority

Each of the four provinces present particular features of localized HIV transmission dynamics. However, to date, successful replications of multidimensional prevention interventions with integrated links to treatment across the country depend on program delivery (Padian et al. 2011). Adopting the Integrated Service Delivery Model in each province will require selecting the optimal mix of HIV prevention and treatment programs, primarily for PWID and their sexual partners, MSWs and hijras, as well as FSWs and their sexual partners, informed by local epidemic appraisals at the provincial level. The continuum of services suggested in the Integrated Service Delivery Models is imperative to ensure that the community-based prevention leads to increased number of most-at-risk populations to HIV testing and treatment, while in the current context the chain of referral is often interrupted before HIV testing leading to loo demand and uptake of ART.

Furthermore, particular attention and analysis shall be focused not only on "which 
interventions to invest on and implement" but also on "how to implement a high-quality continuum of services" that ensure uptake and service utilization by the concerned populations. In this regard, the implementation of the optimal mix of HIV programs warrants the design of locally adapted service delivery models, funded, implemented, and evaluated to ensure that key populations at risk are reached with services at the required coverage and intensity to cause change and impact the HIV epidemic trajectory. In order to achieve effective implementation, studies of intervention effectiveness and implementation efficiency need to be included in the monitoring and evaluation agenda, in order to continuously appraise the implementation practices and quality and to inform efficient operational adjustments.

In this context, increased funding through Provincial Governments will be crucial to ensure effective and efficient implementation and sustainability of actions at community level and impact the trajectory of HIV epidemic in Pakistan. As donor resources for AIDS programs decline, it will be essential to effectively respond to highly concentrated HIV epidemics and maintain national and international investments for comprehensive, focused and well-aligned evidence-based responses that target HIV transmission among most-at-risk populations and their partners. 


\section{Introduction}

With an estimated total population of $184,400,000$, the Islamic Republic of Pakistan is the sixth-most populous country in the world (Population Reference Bureau 2012). It is an ethnically and geographically diverse country with a rich social and cultural heritage. Since the first outbreak of HIV infections in Sindh in 2003-04, national and international actors swiftly responded to evidence of the existence of a concentrated epidemic among PWID through the implementation of harm reduction programs. HIV prevention interventions have been implemented for FSW and, to a lesser extent, for MSM and HSWs as well. By the mid-2000s, needle syringe exchange programs (NSEP) were being implemented in large cities.

Overall, Pakistan has made strides over the last decade in its AIDS response, with active surveillance, considerable research, both governmental and non-governmental prevention and care activities, and treatment since 2005-06. However, the HIV prevalence among PWID has not declined, coverage of current prevention and treatment programs remains limited and the gains made to date are threatened by internal and external factors. Pakistan has seen a marked decline in external funding and decreasing donor focus on HIV-specific support in 2010-11, which resulted in the disruption of services for PWID and other risk populations.

Against this background, this report attempts to review and synthesize available data on HIV in Pakistan and to use these data to suggest strategic priorities for the next phase of the HIV response in an effort to improve the allocative efficiency of resources and effective and efficient implementation of the response. There are two primary objectives:

1. Descriptive epidemiology: The review has brought together available data from published sources, grey literature and other reports to describe the current epidemiology of HIV in Pakistan.

2. Targeting the response and resource allocations: Available evidence was used to suggest a more focused, targeted, cost-effective and evidence-based response to HIV epidemic in the country. This effort is aimed at ensuring that resources are allocated to programs and services that will have the highest impact on reducing new infections. 


\section{II.Epidemiology Methods}

\section{Search Strategy}

We conducted a systematic review of the published and unpublished literature on the epidemiology of HIV in Pakistan. Systematic searches of the published databases PUBMED and EMBASE were conducted on March 8, 2011and updated through December 1, 2011 to identify eligible articles that would inform the review using appropriate MESH terms for Pakistan and HIV. There were no language restrictions. To identify additional published or unpublished articles we solicited data from the National AIDS Control Program of Pakistan and local partners including the Provincial AIDS Control Program (Sindh) and the HIV/AIDS Surveillance Project (HASP). To inform our review, we also electronically solicited articles from all four Provincial AIDS Control Programs, as well as from UNAIDS, the World Bank, UNICEF, UNODC, UNFPA, UN Women, USAID and NGOs representing or working with people who inject drugs (PWID), migrants, people living with HIV (PLWH) and experts working in the area of HIV/AIDS. In addition, we reviewed non-peer reviewed reports published by the aforementioned entities. Finally, we conducted stakeholder meetings in March 2011 in Pakistan to gather additional information, and then triangulated data from several sources. Although our search did not have any date restrictions, we focused on findings from the last six years and only evaluated pre-2005 data relative to risk groups about whom there was insufficient data from 2005 on. We registered to receive electronic notifications from PUBMED through December 2011 in an effort to identify additional relevant studies.

\section{Eligibility Criteria}

To estimate the burden of HIV, we included studies that reported on prevalence odds of HIV or AIDS measured by biological tests conducted among the general population or among high risk or vulnerable sub-populations (returning migrants, prisoners, truck drivers, blood donors or recipients, people who inject drugs, male and female sex workers and hijra sex workers or their partners). Population-based surveys that estimated the relative population size of these high-risk groups were also included. Studies that evaluated the shared risks of HIV, Hepatitis C, and Tuberculosis were also reviewed in order to understand their role in the HIV epidemic and shared risk factors. Our criteria allowed for the inclusion of all quantitative studies, irrespective of study design (controlled or uncontrolled). These could be cross-sectional surveys or cohort studies. Qualitative studies and case reports of $<30$ participants were also reviewed in an effort to understand the context of risk behavior. 


\section{Data Abstraction}

We imported data from eligible studies into a preformatted Excel spreadsheet, which provided details on the source of the study, the province, city or district and year in which it was conducted, and the population's samples (PWID, MSM, and male, female and transgender sex work). ${ }^{3}$ We also extracted data on the prevalence of HIV confirmed by biological tests. Two independent reviewers reviewed titles and abstracts, determining their eligibility for inclusion in the review. We cross-checked journal published versions with those provided by stakeholders to avoid duplication of studies and included the most recent ones. Two reviewers, independently and in duplicate, extracted data on included studies. Any discrepancies between the reviewers were resolved by consensus and adjudication by a third reviewer.

\section{Study Quality or Risk of Bias of Included Studies}

Since we anticipated that randomized controlled trials or prospective or retrospective cohort studies would be unlikely, the cross-sectional studies or surveys were evaluated for their validity. To assess the studies' quality or risk of bias, we extracted information on the sample size, the methods of sampling and recruitment, whether the survey was pilot-tested as well as the proportion of non-responders, when available. We did not assign any numerical grade for quality but reported on the elements of quality among the included studies. Cross-sectional prevalence estimates can provide reliable estimates of size among different risk groups and prevalence of HIV among these risk groups.

\section{Statistical Analysis}

To estimate the prevalence of HIV among risk groups, when appropriate we planned to pool HIV estimates from surveys using a random effect model and tested for statistical heterogeneity using $\mathrm{I}^{2}$. All statistical analysis was carried out in Stats Direct. Statistical significance was set at two-sided alpha of 0.05 .

Using available epidemiologic surveillance data on at-risk populations, size estimates for these populations from the HASP, and an estimated general population prevalence of 0.1 percent of reproductive-aged adults, we conducted a population attributable risk analysis for PWID, FSW, MSW, and HSW (Table 1). Since population-based estimates on the proportion of anal sex between men who have sex with men was not available for Pakistan, we used very conservative estimates of anal sex behavior from similar

\footnotetext{
${ }^{3}$ People Who Inject Drugs (PWID), Men who have Sex with Men (MSM), Male Sex Workers (MSW), Hijra Sex Worker (HSW), and Female Sex Workers (FSW).
} 
epidemics in the Middle East and North Africa (Mumtaz et al. 2010) as well as the best available estimates of HIV prevalence from an RDS study of MSM in Karachi (Khanani 2010) in order to estimate the attributable risk and population-attributable risk of HIV due to MSM behavior outside the context of sex work.

\section{Grading the Strength of Epidemiologic Evidence and Recommendations}

We assigned strength of evidence grades to our key epidemiological findings and policy recommendations using an adaptation of the GRADE rating approach (Guyatt et al. 2008). Our assessment of the strength of evidence was based on the domains of study quality or risk of bias, the consistency of evidence across geographic areas and different studies, the directness of the evidence to the relevant populations and questions, and the precision of the estimates. The additional domains evaluated included the strength of the association (magnitude of effect) and publication bias, impact of plausible confounders and dose-response of the association.

Similarly, our policy recommendations were also assigned evidence grades when applicable based on whether they were obtained from randomized controlled trials or reasonable modeling approaches in similar contexts and addressed these high-risk populations. Since most estimates of prevalence were from cross-sectional studies, we did not downgrade the strength of evidence-based on study design.

Using the above domains when applicable, we assigned four different grades of evidence. Evidence that was obtained from high-quality studies and was consistent from study to study, along with precise evidence led to a recommendation that was graded as high (estimate likely reflects true effect and is unlikely to be changed by future studies). The strength of evidence was downgraded to moderate if the evidence was imprecise, but obtained from reasonable-quality studies and if the findings were reasonably consistent. These estimates likely reflect true effect and are unlikely to be changed by future studies, although the precision of the estimates may vary. If the evidence was primarily derived from low-quality studies and was inconsistent from study to study and was additionally imprecise, we assigned a low strength of evidence. These estimates were unlikely to reflect true effect and may be substantially changed by future studies. Evidence was graded as insufficient when there was insufficient evidence on the finding.

\section{Search Results}

The initial search of PUBMED and EMBASE identified $\mathbf{4 4 5}$ citations. After de-duplication, 321 titles and abstracts were reviewed for inclusion into the systematic review. We 
received 59 studies and reports from local stakeholders and partners. Some $\mathbf{9 7}$ studies provided quantitative data, which were included in the systematic review. Additionally, at the time of submission of the report we also received prepublication copies of the results of Round IV of HIV Second Generation Surveillance in Pakistan.

The PRISMA Flow Sheet of included studies is shown in Figure 2. Wherever possible, these reports were disaggregated by city, province, and risk group and our Data Sheet is partially represented in Tables 2-4. The studies identified were variable in design, quality and limitations. Our assessment of the epidemiological findings was not based on any single study. We report the estimates along with their strength and limitations. Policy recommendations based on the evidence follow in the next section. 
Figure 2: PRISMA Flow Sheet for Systematic Review of HIV in Pakistan

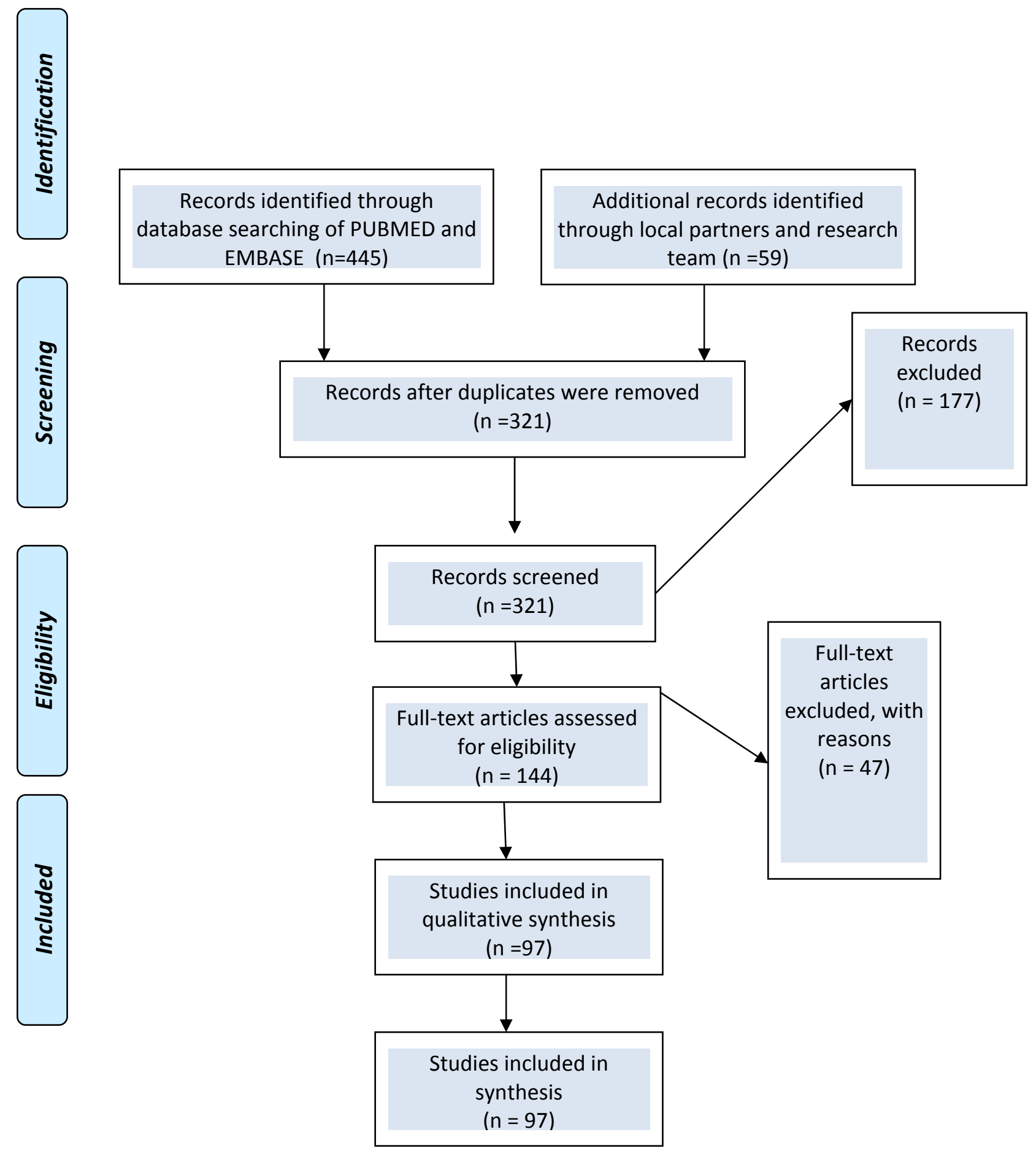




\section{III.Country Context}

Pakistan is administratively divided into four provinces-Punjab, Sindh, Khyber Pakhtunkhwa, and Balochistan, and federal areas or territories - the Federally Administered Tribal Areas (FATA), Pakistan administered Azad Kashmir, Gilgit-Baltistan, and Islamabad Capital Territory (Figure 3). The majority of its population lives in the Indus River Valley's rural areas but also in sizeable urban centers such as Karachi, Hyderabad, Multan Gujranwala, Faisalabad, Lahore, Rawalpindi, Islamabad, Peshawar, and the more outlaying city of Quetta.

\section{Figure 3: Provincial-Level Map}

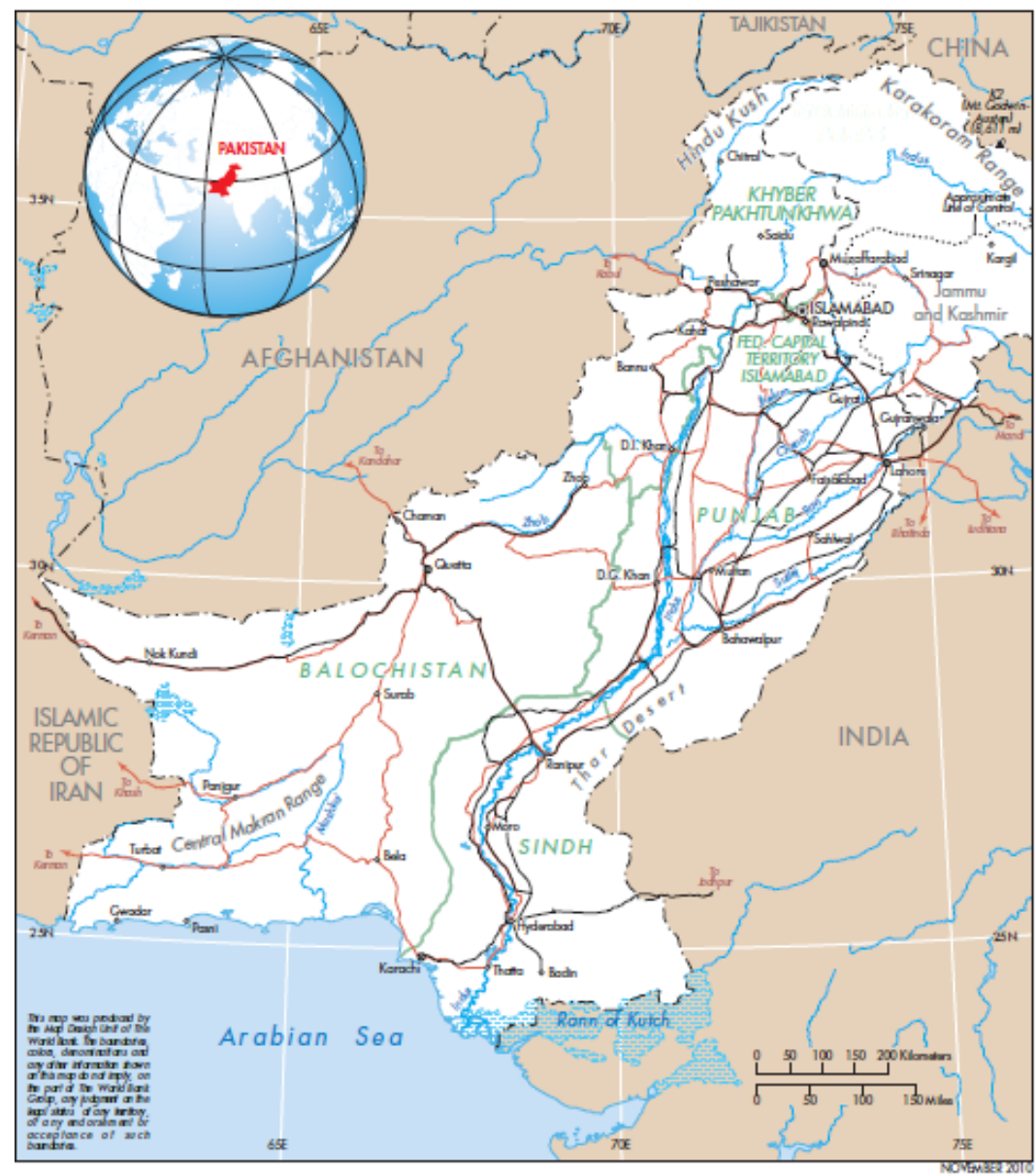

Source: World Bank.

Despite Urdu's status as a national language used across the country, it is considered as the first language to only eight percent of the population. Punjabi is language to 44 percent of the population, Pashto to 15 percent and Sindhi 14 percent (Pakistan Bureau 
of Statistics $\left.2011^{4}\right)$. Since 1980, Pakistan has made steady progress in areas quantified by the Human Development Index (HDI); at a rate of improvement of 1.5 percent per year it ranked $10^{\text {th }}$ among all countries in terms of HDI ranking from 1980 to 2010 (UNDP 2010a). In 2010, Pakistan's Human Development Index Score was 0.49, which is a composite measure reflecting standards in education (the adult literacy rate is estimated at 54 percent among both sexes for those 15 and older); in health, as measured by life expectancy at birth (67 years on average), and a low-middle income standard of living (GNI per capita is estimated at US\$2,678) (UNDP 2010a). However, repeated humanitarian crises, political instability and the global economic down-turn in recent years have likely adversely affected the trends of the last three decades. The majority of the population is living in rural areas, although this trend is quickly changing with the phenomenon of urbanization. There has also been significant labor migration $\mathrm{s}$ to the Middle East and particularly the Gulf States since the 1970s.

Among the total population the ratio of males to females is 1.07 to 1 ; this ratio widens to 1.09 males for every female in the age range of 15 to 64 . Pakistan is experiencing a demographic transition. As the population pyramid illustrates, a substantial portion of the country's population is under the age of 14 (approximately 35.4 percent). The Total Fertility Rate (TFR) or the average number of children that would be born to a woman over her lifetime, assuming she were to survive from birth through the end of her reproductive life, is 3.17, giving Pakistan the second-highest ranking in the South Asia region. Pakistan's TFR is expected to continue to decline, however, and reach replacement levels by 2050 .

\footnotetext{
${ }^{4}$ http://www.pbs.gov.pk/content/pakistan-statistical-year-book-2011
} 
Figure 4: Pakistan Population Pyramid, 2010

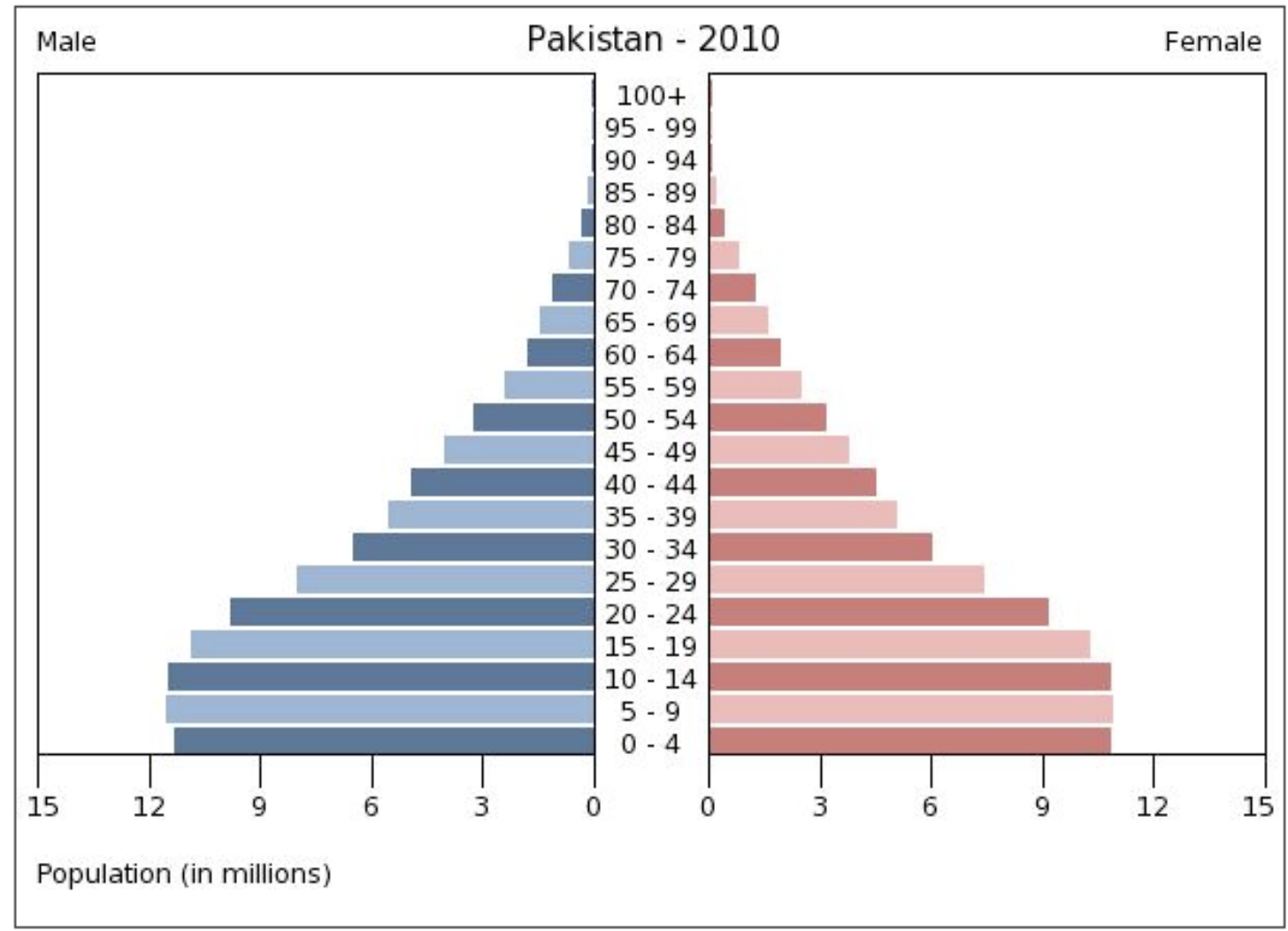

Source: US Census Bureau, International Database 2010.

\section{The Health System}

The health system in Pakistan consists of both public and private systems. The state administers health care through a three-level system. Basic Health Units and Rural Health Care Centers form the primary health care system. Secondary health care, including ambulatory and inpatient care, is delivered by District Headquarter Hospitals and Tehsil Headquarter Hospitals. Tertiary care is delivered via teaching hospitals (WHO 2007). The public health system is largely managed at the district level. Pakistan has a vast network of healthcare facilities, with 968 hospitals, 4,813 dispensaries, 5,345 Basic Health Units, 572 Rural Health Care Centers and 239 Tuberculosis Centers (Ministry of Finance 2010). In 2009-2010 there were more than 135,000 doctors in Pakistan. The private sector is made up of a diverse group of health professionals, including doctors, nurses, pharmacists, laboratory technicians, homeopaths and hakeems, as well as unqualified practitioners. The majority of private hospitals in Pakistan are located in urban areas. The private sector is the largest provider of health care in Pakistan and is largely unregulated. Pakistan has a highly active non-governmental organization (NGO) 
sector, with more than 80,000 NGOs registered under various acts. However, as in other developing countries, the coverage, quality and cost of health care remain an ongoing challenge. Although constitutionally health in Pakistan has been a provincial prerogative, it was jointly administered by both the federal and provincial levels until mid-2011 with the introduction of the $18^{\text {th }}$ Constitutional Amendment and the devolution of the Ministry of Health functions leaving the provinces effectively responsible for implementation (Ali N, Saeed K, 2012).

\section{Gender Inequities and Norms}

Pakistan is a traditional patriarchal and Islamic society. Although socio-cultural and economic environments allow for differing realities, as a whole norms in the country restrict female mobility and still confine women to a limited range of educational and employment prospects at low wages (World Bank 2005). In a 2010 comparative analysis of gender health indicators and gender-sensitive policies in South Asia, levels of female reproductive rights, autonomy and leadership were more limited in Pakistan than in other countries of the region (Gill and Stewart 2011). In addition, there is a large gender gap in literacy, with only 36 percent of females versus 63 percent of males considered literate according to the 2005 census. The maternal mortality rate of 320 per 100,000 live births remains high and is exacerbated by the low number of women giving birth in the presence of a skilled attendant and even lower percentage of women meeting the benchmark of four antenatal visits (Countdown to 2015 2010). The combination of low literacy and limited access to healthcare only exacerbates the difficulties involved in reaching the wives of HIV+ men and those who are at risk or vulnerable.

\section{Political and Security Context}

Pakistan's HIV epidemic and the health challenges the country faces more broadly should arguably be viewed in light of its complex political environment. Security concerns contribute to program complexities and challenges, given an insurgency by militants in certain regions areas. A distinction can be made between humanitarian emergencies-such as are common after natural disasters or in epidemic outbreaksand complex humanitarian emergencies, where armed conflict is either the cause of the humanitarian crisis and internal displacement, as happened in Khyber Pakhtunkhwa and FATA since 2009 but nevertheless complicates public health responses as in other settings of civil conflict. We might consider Pakistan's HIV and related infectious disease outbreaks to be complex humanitarian emergencies. It is also affected by the extent that the cultivation of opiates in Afghanistan and the socio economic and political forces that maintain it are clearly implicated in the high rates of opiate use and dependence in several neighboring countries. It is also further affected by insecurity to the extent that 
some provinces can provide little data on the health of their populations, while in others program costs are increased by the need for security. The devolution of the health services to the provincial level may lessen some of these concerns in more stable areas, but may have an adverse effect in certain other regions.

\section{Social and Legal Context for HIV Response}

The changing policy context within the country plays an important role for the HIV response, particularly among risk groups. Pakistan is an Islamic republic and religion forms the crux of social and public life. Under Islamic law, any form of sex other than between man and wife is haram (forbidden). Sexual encounters outside of marriage, sex work and same-sex contacts are illegal in Pakistan. Penal code 1860, Section 377 prohibits "carnal intercourse against the order of nature" with a maximum penalty of imprisonment for life (UNDP 2010b). Prosecutions for male-to-male sex behavior are thought to be rare but no reliable data is available. According to the UNDP report, overt homosexual behavior is legally censured, however there is more ambivalence in social attitudes on sex between men Such a policy environment impede effective HIV prevention by creating strong barriers for those who would seek care or services, while simultaneously driving sex worker and the Hijra community underground. Furthermore, the report classified the legal system in Pakistan as "highly prohibitive," with criminal laws that are selectively enforced against men who have sex with men (MSM), though there has been some notable improvements in recognition of the civil rights of transgender in 2009 (UNDP 2010b). 


\section{Status of HIV Epidemic}

\section{HIV in the General Population}

Pakistani national adult prevalence estimates are under 0.1 percent (UNGASS 2010). The best available evidence on HIV in the general population comes from routine antenatal HIV surveillance conducted in clinics for pregnant women. In 2008-09, there was not a single case of HIV reported among 2,983 women sampled (venue-based sampling) at Lady Wallington Hospital in Lahore, or among 2,589 pregnant women sampled at the Pakistan Institute of Medical Sciences in Islamabad (Shabbir, Uzma and Abbass 2010). Although these data are somewhat dated, among 118,899 people tested (venue-based) from 1988-1996 in Sindh, only 315 or 0.26 percent were reported as HIV-positive (Hyder et al. 1999). The HASP Round IV Surveillance (NACP 2012) indicates that HIV among the general population continued to show similar trends, with very low prevalence rates. An antenatal surveillance only showed 12 confirmed cases of HIV among 26,510 pregnant women in nine districts for an overall prevalence rate of 0.04 percent. An occupational study among 12,000 mine workers in Mach, Sorange and Muslim Bagh did not detect a single case of HIV. Thus these data are reassuring regarding the absence of a current HIV epidemic among the general population (Strength of Evidence: Modest).

\section{People Living with HIV}

The WHO/UNAIDS EPI model estimates that there were 96,000 people living with HIV in Pakistan in 2008 (UNAIDS 2010). The registered number of HIV infections was less than 4,000 , however, and only roughly 1,900 people are currently receiving ART through the public sector system.

\section{Molecular Epidemiology}

The first analysis of prevalent subtypes in Pakistan reported infection of HIV-1 subtype A among PWID in Karachi, suggesting that the prevalent subtypes in Pakistan are dissimilar to those in other Asian countries where the predominant subtypes are HIV-1 subtypes B, C, and CRF-01AE (Khan et al. 2006; Rai et al. 2010). Phylogenetic analysis of 200 HIV-positive cases revealed these to be subtype A1 $(n=143)$ and CRF02_AG $(n=8)$. This suggested a single highly linked sequence representative of a true outbreak (Pilon et al. 2010). Figure 5 presents the prevalent subtypes of HIV in Pakistan and the region.

An additional study by Rai (Rai et al. 2010) indicated that the HIV-1 subtype A strains from Pakistan among a community of PWID shared typographic similarities to HIV circulating in Africa, and there was possible evidence of a "founder effect." 
Figure 5: Prevalent HIV-1 Subtypes in Asia

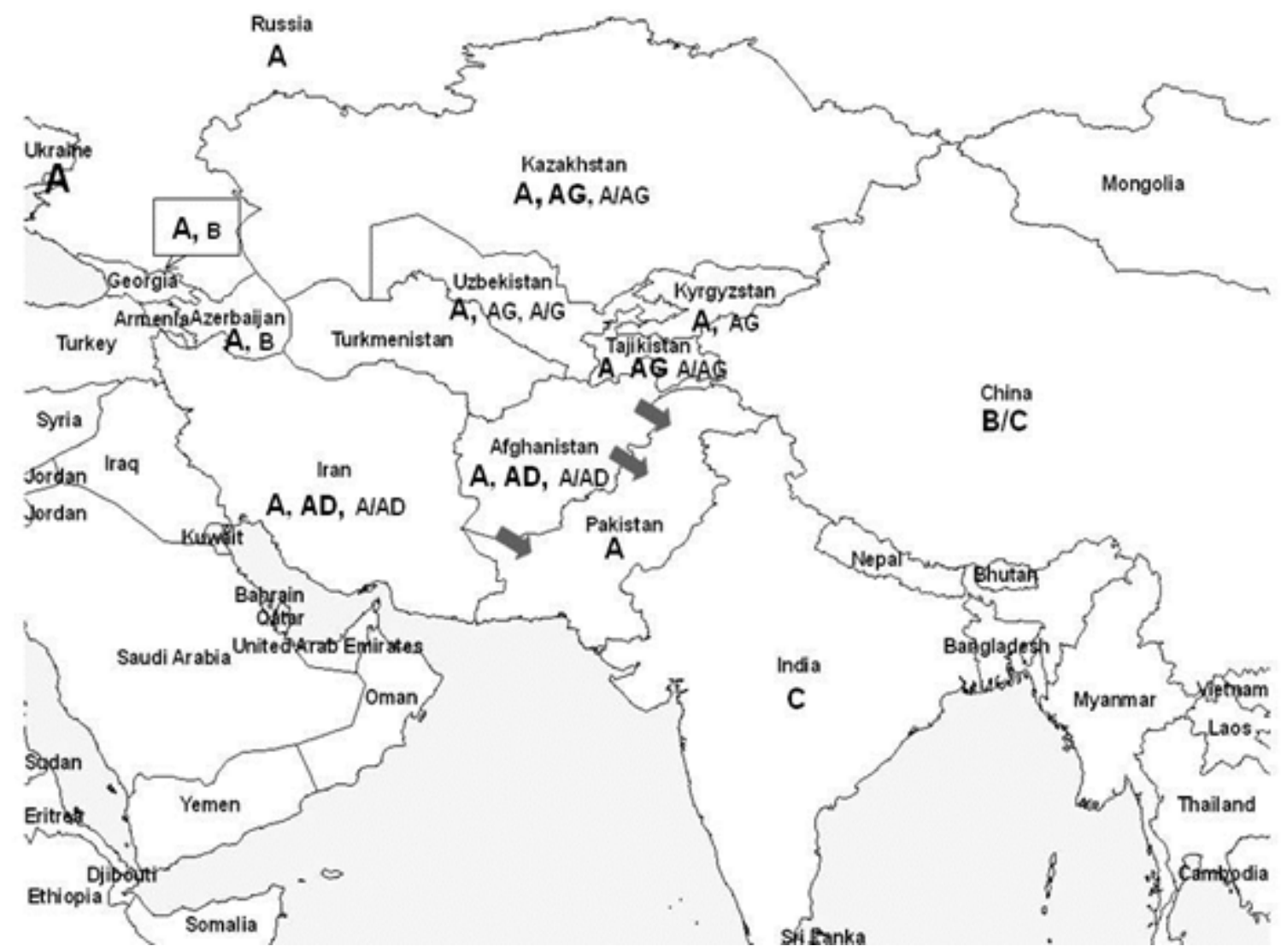

Font size for these subtypes denotes relative proportion of prevalent subtypes specific to each country. Data are adapted from other sources (Beyrer 2009; Sanders-Buell 2007; Carr 2005; Rai 2010).

\section{Size Estimation of High-Risk Groups}

The most robust data on high-risk group size estimates comes from NACP in 2007. It contains disaggregated estimates at the city (roughly 103 cities) and province level. The National Round III Report from 2008 did not provide this level of data for size estimation to be carried out, but did offer quality surveillance data on HIV prevalence stemming from 12 major cities across the country. Although there are some limitations with respect to the choice of researchers (service providers) for sample recruitment, the data and the sample size estimates nevertheless appear consistent. In an attempt to provide the most targeted data for planning purposes, the decision was made to utilize the HIV prevalence estimates from NACP III and the 2007 size estimations.

The 2007 exercise estimated that 41 percent of all most-at-risk populations (MARPs) were FSWs, size estimate 136,300 FSWs. PWID constituted 27 percent of all MARPs, size 
estimate 91,112. For their part, MSWs constituted 19 percent of all MARPs, size estimate 62,636. At 42,877, HSWs constituted 13 percent of all MARPs. The confidence interval around these estimates was not reported. However these national projections of most-at-risk population sizes must be interpreted with caution, given that data collected from urban samples were extrapolated to the whole population of Pakistan by use of a rural factor. This includes people inhabiting rural areas, where the majority of Pakistan's population resides, and actual numbers of MARPs are unknown. Other extrapolations have reported lower or higher estimates (i.e. $\approx 91,000$ PWID), but the overall pattern of data suggests that FSWs are the largest risk group, followed by PWID, MSWs and HSWs.

Figure 6: Proportions of PWID, and SW Sub-Groups among At-Risk Populations, 2007

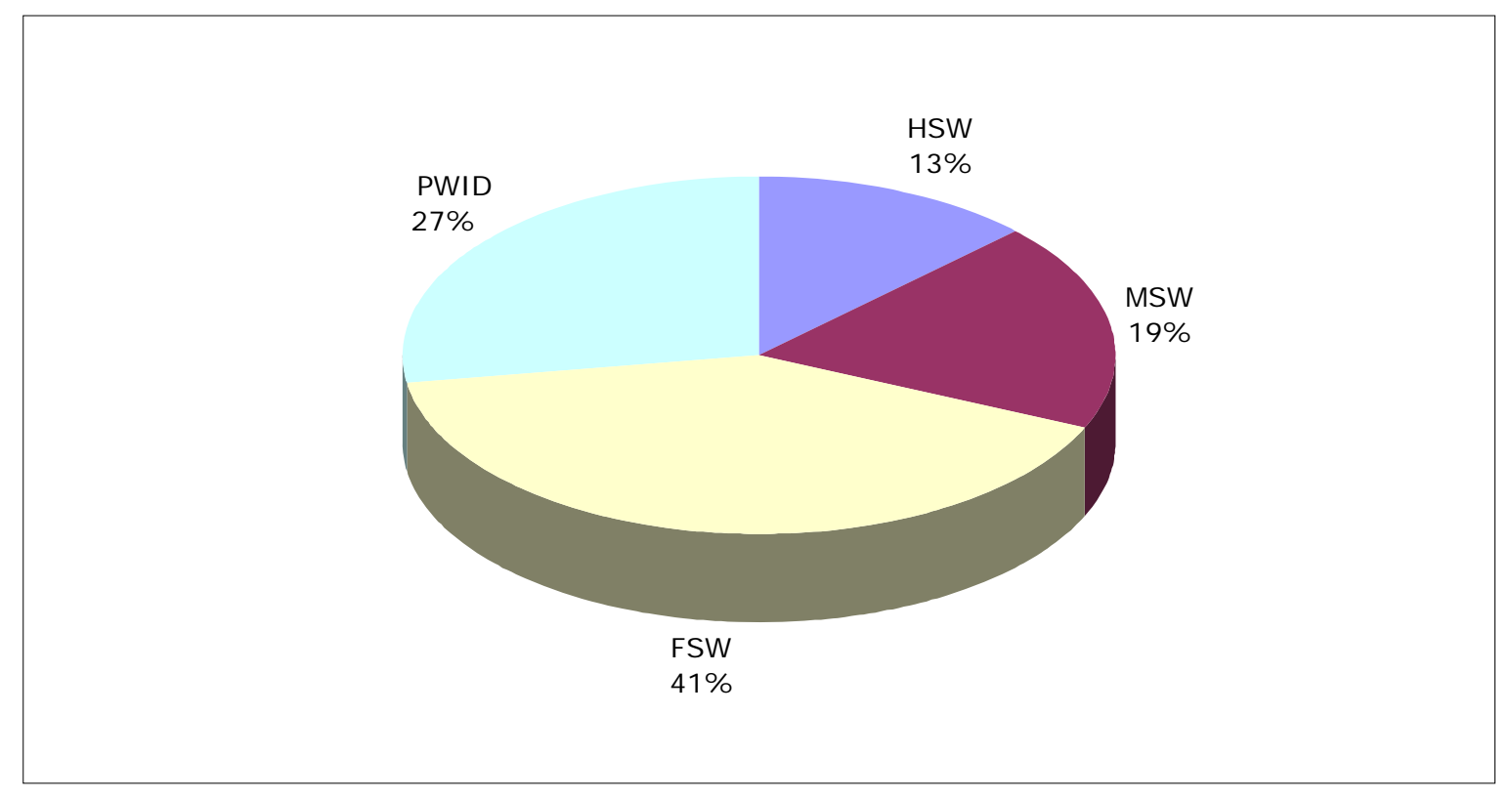

Source: National AIDS Control Program 2007

There were substantial variations and heterogeneity from province to province (Emmanuel et al. 2010), but Sindh had the largest proportion of high risk groups. As expected, the overall numbers of FSWs were significantly higher in the larger cities (Lahore, Faisalabad and Multan) in comparison to smaller cities (Bannu and Rawalpindi). Similarly, among PWID, the highest reported numbers were from Karachi, Faisalabad and Sargodha, with the lowest size estimates reported from Peshawar, Bannu and Quetta. Among MSWs and HSWs, the highest numbers for both groups were calculated in Larkana (Sindh), whereas the lowest for both was in Bannu in Khyber Pakhtunkhwa. 
Similar to the first round of surveillance, the HASP II data provided largely similar results with some methodological improvements, including triangulation of results and community involvement in size estimation of high-risk groups across 12 major Pakistani cities. They estimated there were roughly 167,501 FSWs (4.4 FSWs/per 1000 adult women), 102,042 PWID, 71,911 MSWs (1.7/per 1000 men) and 39,363 HSWs (0.9/per 1000 men) in Pakistan (Emmanuel et al. 2010). The results of HASP Round IV surveillance revealed that the size estimates for different high-risk groups was as follows: PWID 3.7/1000 adult males, FSWs 7.2/1000 adult females; HSWs 1.9/1000 adult males; MSWs 1.6/1000 adult males.

\section{Populations at Greatest Risk}

Figure 7 below displays the trends of HIV prevalence among high risk groups from 2005 to 2009, according to the 2010 UNGASS reports. HASP Round IV surveillance revealed that unweighted HIV prevalence among MSWs, HSWs, FSWs and PWID was estimated at 1.6 percent, 5.6 percent, 0.6 percent and 27.2 percent respectively, with provincial heterogeneity.

Figure 7: HIV Prevalence Trends among MARPs, 2005-09

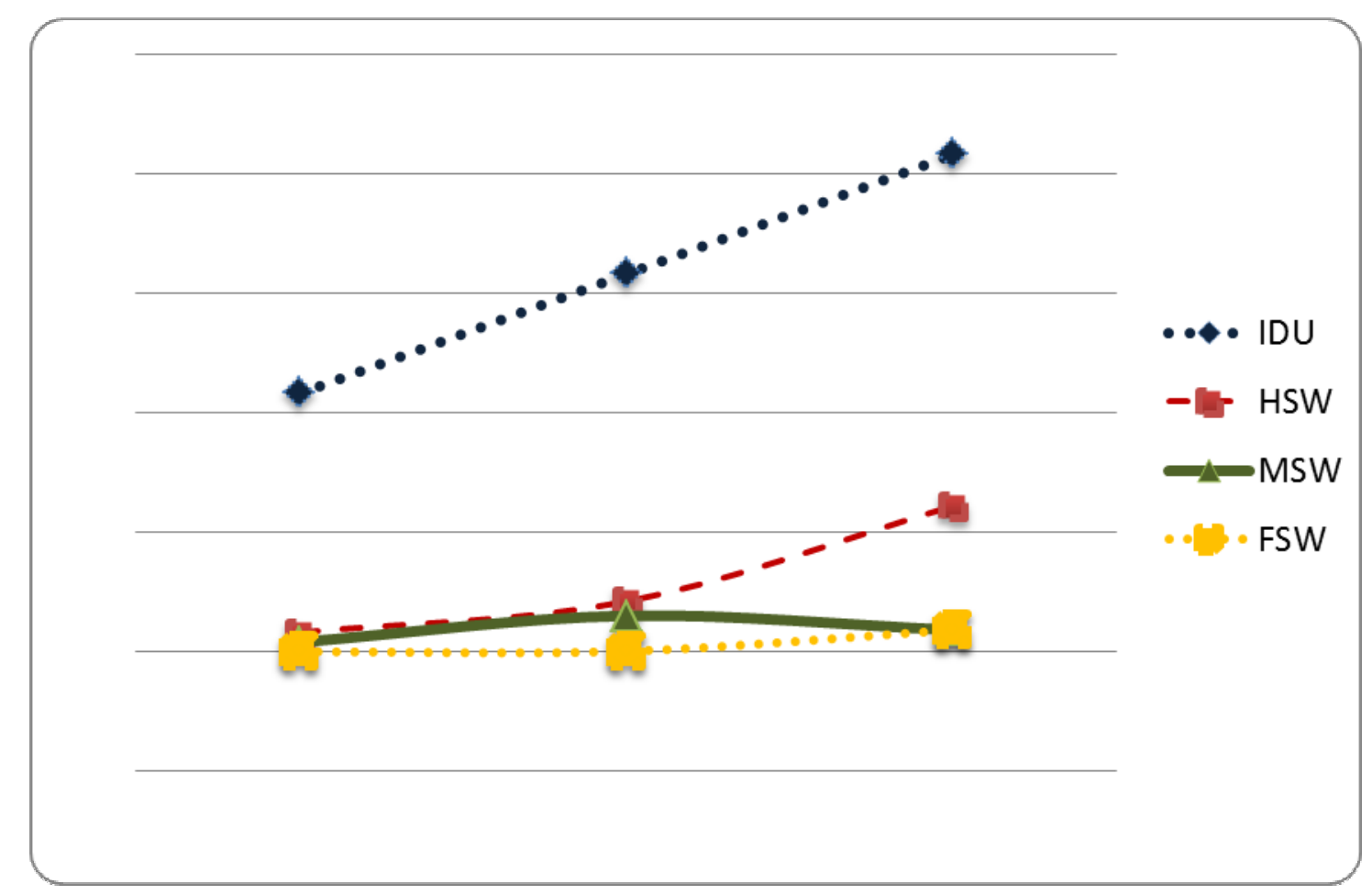

Source: UNGASS 2010 Country Report. 


\section{People who Inject Drugs (PWID)}

PWID constitute the core group driving the HIV epidemic in Pakistan and are classified as high-risk in multiple research reports and articles (NACP 2005; NACP 2008a; Bohkari et al. 2007; Kuo et al. 2006; Haque et al. 2004; Khan et al. 2009; Nai Zindagi 2009; Nai Zindagi 2008; Khan and Khan 2010; Atlaf et al. 2007; Atlaf et al. 2009b; Afridi, Khan and Fatima 2010; Emmanuel and Fatima 2008). The demographic profile of PWID and their patterns of drug use, along with other risk behaviors, are described in peer-reviewed articles and presented in Table 2. These reveal a heterogeneous pattern of drug use and a diverse epidemic in different cities. Data were too heterogeneous across sites and rounds for successful meta-analyses.

PWID reports have consistently shown very high rates of HIV since 2003 in multiple surveys conducted by the NACP, NGOs, and various researchers through peer-reviewed studies. The national prevalence of HIV among PWID is estimated to be 20.8 percent $(\mathrm{Cl}$ 19.4-22.3) (NACP 2008a). This ranges from as low as 12.99 (8.6-17.2) in Peshawar to as high as roughly 30.4 percent (26.0- 35.0) in Hyderabad according to the HASP III (NACP 2008a). Figure 8 below provides 2008 national prevalence estimates of HIV among PWID in select cities.

A multistage cluster sample had previously reported a very high rate of HIV among PWID in Sargodha in 2007, in which 205 out of 400 PWID tested positive to reach 51.25 percent (95 percent $\mathrm{Cl}$, 46.5-55.4 percent) likely due to the high-risk practice of mixing (Emmanuel et al. 2009). A focus group behavioral study of 150 PWID from Sargodha demonstrated high-risk injection preferences, including "double pumping," which allows for mixing blood and drugs in the syringe, and "scaling," a practice of leaving $2 \mathrm{ml}$ in the syringe for the injector (Khan 2009). 
Figure 8: National Estimates of HIV Prevalence among PWID in Select Cities, 2008

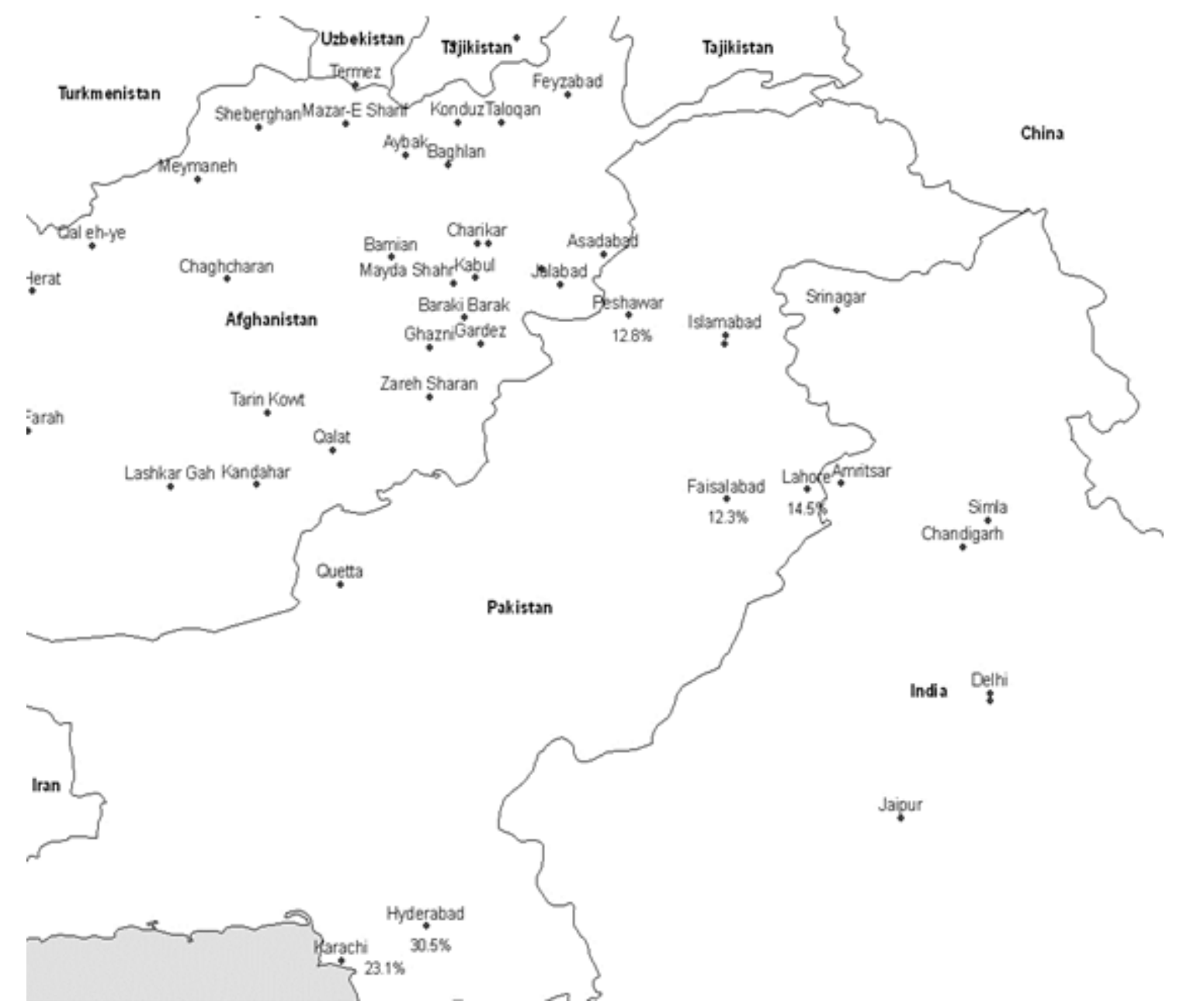

Note: The total estimated prevalence of HIV among PWID in Pakistan in 2008 was 20.8 percent Source: NACP 2008.

\section{Recent Epidemiologic Trends among PWID}

More recently, in 2009 Nai Zindagi conducted a rapid situation assessment among PWID in four cities of Punjab. They mapped geographic areas to identify sites in four cities and estimate the number of street-based PWID sites and users in the four cities of Mandi Bahaiuddin (32 sites, 828 users), Rawalpindi (40 sites, 451 users) Sheikhpura (44 sites, 607 users) and Gujranwala (20 sites, 480 users). HIV-positive rates were as high as 52 percent (156/300) in Mandi Bahaiuddin, 23 percent in Rawalpindi (69/300), 21 percent in Sheikhpura (63/303) and 7.92 percent Gujranwala (24/303)-substantially higher than previous HIV estimates of 1 percent in Gujranwala and 3 percent in Rawalpindi. The extremely high rates in Mandi Bahaiuddin were attributed to injection of local marphia (a morphine-based locally fabricated tablet). While most data on PWID comes from male PWID, there have been some recent reports of HIV among female PWID in 
Pakistan, with their patterns of drug use being linked to pharmaceuticals rather than heroin. However, female PWID are likely to make up a quite small proportion of total users with UNODC estimates of .2 percent in 2008 (Bergenstrom et al. 2010). The HASP Round IV Surveillance indicates that among the PWID population, only 38.6 percent injected with a new needle and 31.2 percent used someone else's needle (NACP, 2012).

There is little evidence from the studies that the epidemics of HIV among PWID have been transmitted to the general population. Rather these have been self-sustaining epidemics among the core at risk groups. 


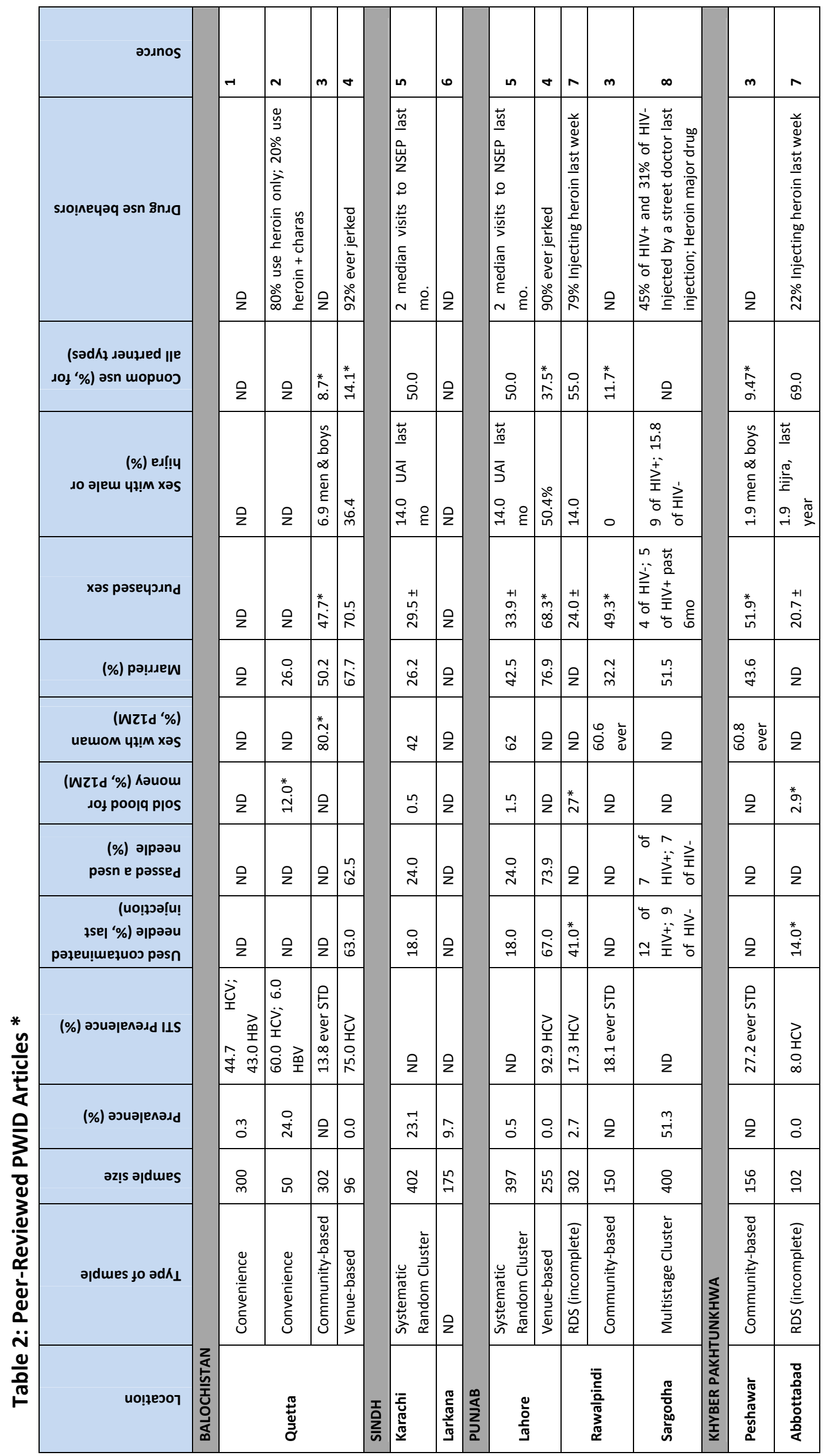

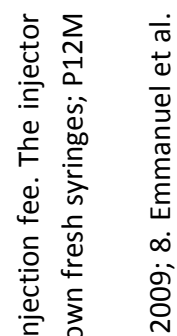

कू त

ब声感

었 요 푼

늠

$\bar{\varepsilon}$ वे

$\sim \pm N$

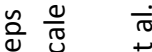

플

त

m

Ч

岸号

ᄒ

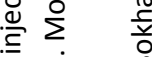

" 㐫

$\frac{0}{\pi}$

导

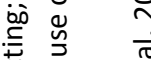

$\stackrel{\otimes}{\square}$

党

車

过

齐 क्ष

$\pi$ 능

总产

웜

ह $m$

잉

흠 응

a o 0

妾 索

㝋䓃

ज़

단 $\frac{\pi}{\sqrt{2}}$

$x$

凶ั

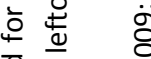

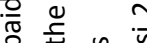

$++\frac{n}{\bar{\sigma}}=\frac{0}{ \pm}$

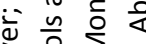

.

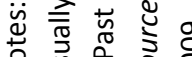




\section{Wives of PWID}

Approximately 50 percent of PWID in Pakistan are married (Nai Zindagi 2008). In a recent convenience sample of 459 PWID couples, 5 percent of wives of PWID in Sargodha (n=103), 15 percent of wives of PWID in Faisalabad $(n=13), 10$ percent of wives of PWID in Lahore $(n=11)$ were positive for HIV, but the sample size for these estimates is too small to draw any definitive conclusions (Nai Zindagi 2008).

\section{Heroin Trafficking}

Pakistan shares a large and porous border-including the Khyber Pass-with Afghanistan, the world's largest producer of illicit opium (UNODC 2010). The country is the transit point for nearly two-fifths of the opium produced in Afghanistan. The processing of this takes place on the Pakistan-Afghanistan border. There is some evidence of poppy cultivation in the Federally Administered Tribal Areas, as levels of poppy cultivation rise during periods of insurgency in the region. In the case of other countries in South Asia, drug abuse and addiction are exacerbated along trafficking routes (Beyrer et al. 2000). However, molecular epidemiological studies among drug trafficking routes in Pakistan are limited. A recent phylogenetic study raised the interesting possibility that Xinjiang province in China, bordering Pakistan, may be an important conduit for the transmission of HCV-3 among drug trafficking routes in this region (Liu and Zhang 2011),

Afghanistan is the leading producer of the world's opium and heroin. Approximately 93 percent of the world's opium and heroin originate in Afghanistan (UNODC 2010). About 80 percent of Afghan opium production is trafficked via Pakistan and Iran, the remainder through central Asia. Since 2006, much more opium has been produced in Afghanistan than can be consumed worldwide. Drugs from Afghanistan have an annual value of 65 billion dollars and cater to 15 million users worldwide. The scale of regional heroin production and trade is a challenge for all partners, and at least partly explains the high rates of heroin use apparent in the region. It is important to note that the UNODC has forged a Triangular initiative, launched by Pakistan, the Islamic republic of Iran and Afghanistan, in hopes to combat drug trafficking in the region.

\section{Hijra Sex Workers (HSW)}

Hijra are biological males who adopt a female gender identity, which can include wearing women's clothing and fulfilling female gender roles. Hijra have specific community affiliations and social and cultural functions throughout South Asia. Some hijra, but not all, are postoperative transsexual women. The peer-reviewed studies describing hijra risk behavior and characteristics are presented in Table 3. Among HSWs, the HASP Round IV of surveillance revealed the highest prevalence was 15 percent reported in Larkana, followed by Karachi at 


\section{3 percent, Sukkur at 6.2 percent, and Lahore at 5.3 percent.}

In terms of burden of HIV the second most afflicted risk group includes hijra sex workers (HSW). There is a paucity of high-quality data on these risk groups in Pakistan. However, whatever data is available suggests an emerging epidemic. Round III of the National Surveillance reported estimates of HIV prevalence as high as 6.3 percent (95 percent $\mathrm{Cl}$ 5.0-7.7 percent) among HSWs (NACP 2008a). There were wide provincial variations, with the highest rates of HIV reported among HSWs in Larkana, Sindh 27.6 percent (95 percent $\mathrm{Cl}$ 21.4- 33.9) and the lowest prevalence reported among HSWs in Peshawar (1.24 percent, 95 percent $\mathrm{Cl}, 0-2.95$ ). The prevalence rate in Karachi, Sindh was 3.6 percent (95 percent $\mathrm{Cl}$ 1.2-6.1 percent). These represent worrisome trends for an increase in HIV compared to Round I of the NACP, where the HIV rate among this group was less than 1 percent (NACP 2005).

Apart from the NACP surveys, the published literature on the risk behavior of HSWs was largely consistent with the above findings. Studies have dealt with the various typologies of HSW in Pakistan with provincial variations (Rajbali et al. 2008; Rehan, Chaudhary, and Shah 2009; Shaw et al. 2011). A cross-sectional survey in eight cities (Faisalabad, Hyderabad, Karachi, Lahore, Multan, Peshawar, Sukkur, Quettta) among 1,162 HSWs revealed that they were reportedly older, used more drugs during sexual encounters and were less likely to report condom use during last anal sex than their MSW counterparts ( $n=1,532$, non-hijra sex workers) (Shaw et al. 2011). These studies also highlight the unique vulnerabilities of hijra, including lack of adequate representation in policy and planning and barriers to accessing care.

Although the data are largely qualitative, HSWs appear to have limited access to voluntary counseling and testing and antiretroviral services. They are reluctant to use the same drop-in centers as other high-risk groups frequent. Since the HSW community in Islamabad is not as large as in Lahore, this should not be generalized. Only two HSWs were reportedly on antiretroviral therapy, among more than 1,000 patients accessing free antiretroviral therapy at the Pakistan Institute of Medical Sciences in 2011. The sexual networks of HSWs may only overlap partially with that of PWID in certain cities. For instance, HSWs in Lahore were more likely to report sex with a PWID, compared with MSWs, providing unique opportunities for interventions targeted at both risk groups (Shaw et al. 2011). Apart from Lahore, the sexual networks of HSWs and PWID are distinct. Thus interventions need to consider the aggregate influence of sex work, but also their regional heterogeneity.

In the absence of adequate representation, there is very little activism around the preventive and treatment needs of HSW. However, the hijra are bound by a unique sense of community, leaving room for cautious optimism (Rajbali et al. 2008). The recent progressive judgments of 
the Pakistan Supreme Court asking the National Database and Registration Authority to not verify the sex of transgender individuals through a medical board when issuing a national identity card also raises optimism for the future of this community. 


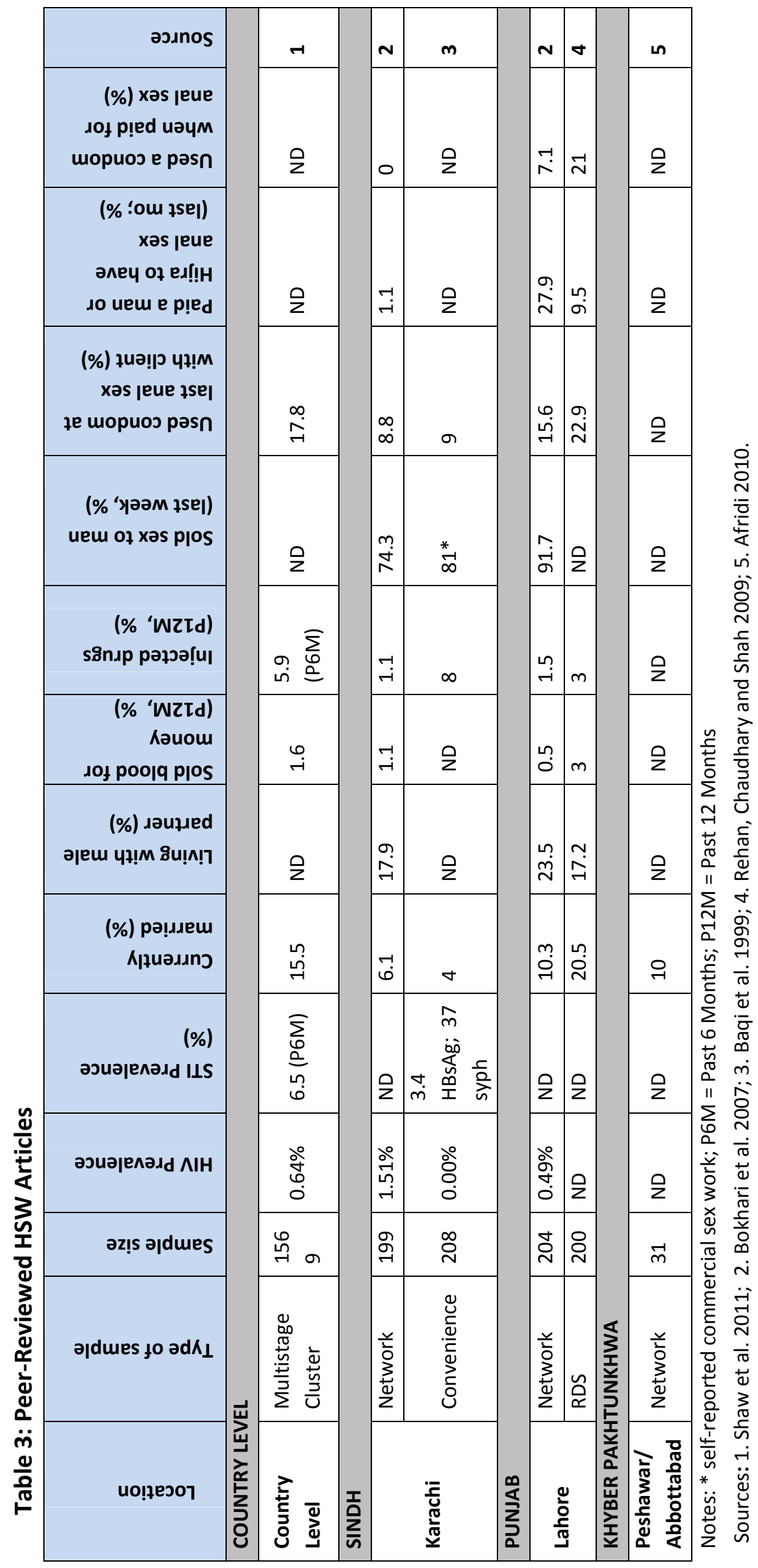




\section{Male Sex Workers (MSW)}

Traditionally, male sex workers (MSWs) have been grouped with HSWs in most surveys. Again, there is a paucity of data on these risk groups in Pakistan. What data is available suggests an upward trend in HIV infections and cause for concern given risk behaviors. MSWs reported very low rates of ever having undergone an HIV test, ranging from 6.44 percent to 8.9 percent (Hawkes et al. 2009; Afridi, Khan and Fatima 2010) and lower rates of reported condom use than in the national IBBS. MSWs currently married ranged from 14.3 percent to 18.3 percent and PWID among MSWs was low, with no reported proportion higher than 4.9 percent. The published literature describing MSW risk behavior and characteristics is shown in Table 4. The reported prevalence rate of HIV among MSWs was 0.75 percent (95 percent 0.3-1.5 percent). This represents a minor upward trend compared to Round I MOH, where reported rates of HIV were as low as 0.45 percent (95 percent $\mathrm{Cl}$ 0.2-0.9 percent).

There are substantial provincial variations. Data available from Sindh indicate that the prevalence rates of HIV among MSWs were 2.9 percent (6/204) in Karachi and only 0.5 percent $(1 / 200)$ in Larkana, according to Round III surveillance. Although the overall HIV prevalence rates are less than $<1$ percent, low levels of education, high frequency of sexual acts (average anal sex $=31$ customers in a month) with low levels of condom use at last sexual encounter $(\approx$ 21.5 percent) place them at high risk for STIs (Shaw et al. 2011), with substantial intercity heterogeneity. The HASP Round IV of surveillance indicated that among MSWs, the highest prevalence rates were reported in Karachi at 5.9 percent, Larkana at 3.1 percent, Sukkur at 2.2 percent, and Multan at 1.9 percent (NACP, 2012).Data on clients of sex-workers are also limited. 


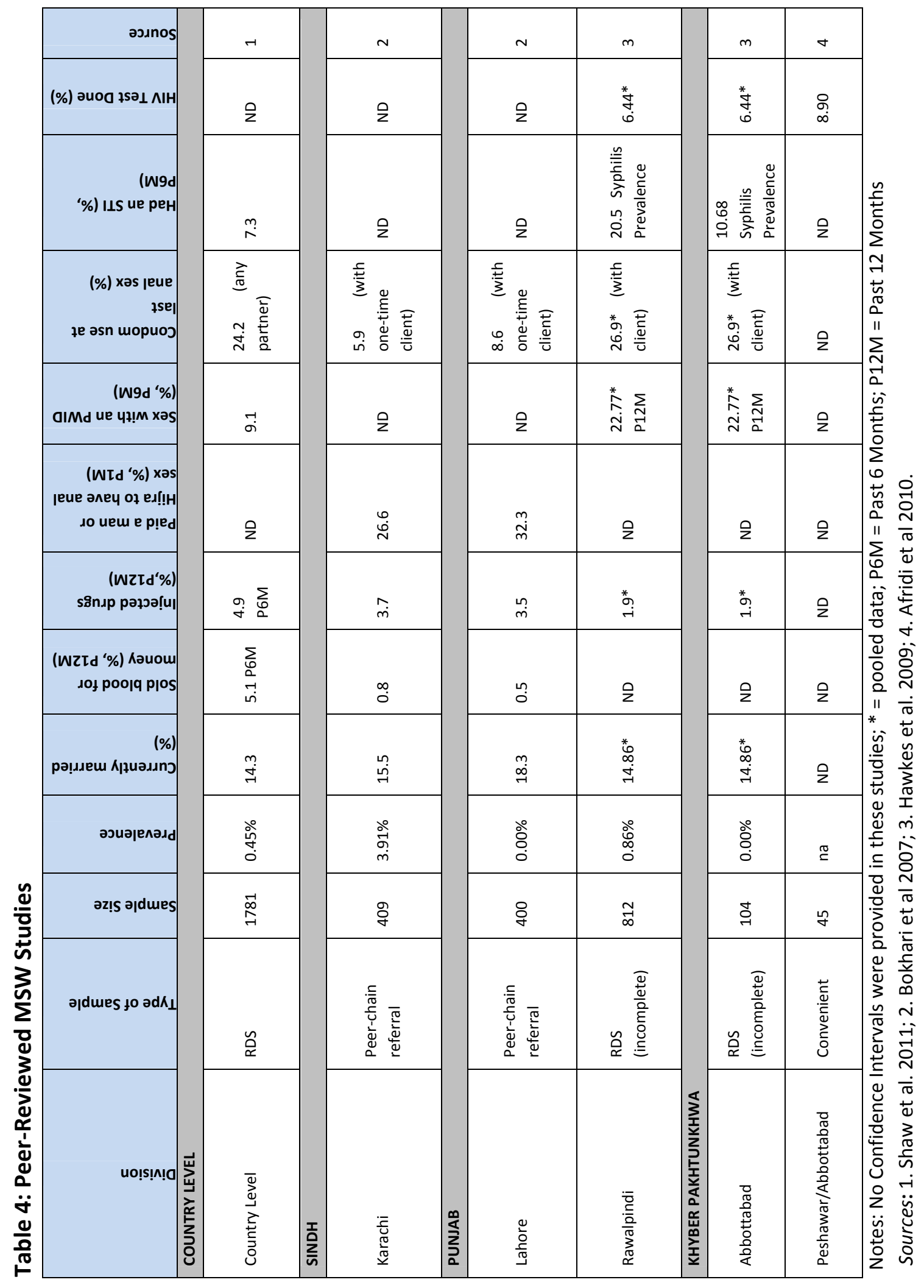




\section{Female Sex Workers (FSW)}

Female sex workers constitute the largest at-risk population in Pakistan. The prevalence rates of HIV among FSWs were very low in the National Survey Round I (0.19 percent, 95 percent $\mathrm{Cl}$, and 0.07-.45) and hence they were not included in Round III. A respondent-driven sampling study in 2007 conducted in Rawalpindi, Punjab ( $n=426)$, Punjab and Abbottabad in Khyber Pakhtunkhwa ( $n=107)$ did not report any HIV among sampled female sex workers (Hawkes et al. 2008). A slight increase was documented in a special round of surveillance surveys in 2009-2010, with infection rates ranging from .99 percent in Lahore (4/406) to 2.24 percent (9/401) in Karachi (Abbas 2010).

An HIV prevalence rate of 0.6 percent was reported in the latest round of 2011 IBBS surveys, with significant variations across provinces. Larkana and Karachi in Sindh reported the highest prevalence of HIV among FSWs (1.9 percent each), followed by Haripur (0.9 percent), Sukkur (0.8 percent), and Lahore (0.5 percent) (NACP 2012). A national survey estimated the total number of FSWs at 136,000 (NACP 2008), noting that this figure might be low given the clandestine and illegal nature of sex work (Emanuel 2009). The typology of female sex work, determined by place and mode of operation, is closely linked to HIV- and STI-related risks. Typically, brothel-based sex workers operate in stable locations, licensed for entertainment, known by clients and brokers and managed by a "madam" or other individual (FHI 2009; Emanuel 2008; NACP 2012). Kothikana or

"grand house" is a colloquial expression used to depict small clandestine premises rented and managed by madams, located mainly in residential areas, where a small number of FSWs live and entertain clients. Female sex workers usually come from locals other than the city in which they work (FHI 2009). Street-based female sex workers operate and solicit clients in "pick-up points," for example on the street, in market places and at bus stops. Sexual transactions then occur at a venue chosen by the FSW and/or the client (NACP 2012). The category of home-based FSW includes female sex workers that live with their families. They are part-time and rely on network operators to communicate with the clients and as well as for arrangements where the sexual activity takes place (NACP 2012).

Following the global trend, the profile and typology of female sex workers is changing in Pakistan. Brothel-based FSWs currently make up only approximately 2.2 percent of this group (NACP 2012), while the number of female sex workers operating independently-in hotels, beauty parlors, or contacting clients through mobile phones-is increasing. These volatile groups have not been included in the rounds of IBBS, and there is scant information related to the magnitude of HIV infection and related risk factors and practices among them. FSWs report an average of three clients per day, and a monthly average of 50+/-37.2 clients, without much variation by typology. More independent sex work appears to bring benefits in terms of money management as well as increasing the risk of arrest and violence (IBBS 2009). IBBS 2011 indicates that condom use by FSWs with their clients was generally very low. Only 20.6 percent reported consistent condom 
use with non-paid clients and 50 percent of FSWs reported using a condom during their last vaginal intercourse (NACP 2012). Almost universal male circumcision in Pakistan might be the key factor in maintaining low HIV prevalence among the FSW population. However, the diversification of female sex work typology coupled with increased vulnerability and the large presence of this population will warrant particular attention in seeking to maintain low prevalence.

\section{Men who have Sex with Men (MSM)}

Pakistani society is conservative and male-to-male sex behavior is illegal in the country. Thus, very little reliable data is available on HIV rates among MSM, other than those who operate as sex workers, as they have not been included in HASP estimates. One respondent-driven sampling study $(n=396)$ conducted in the three Sindh cities of Karachi, Sangar and Larkana had HIV prevalence rates among MSM ranging from as low as 2.78 percent in Sangar to as high as 18 percent in Larkana (Khanani et al. 2010).

\section{Sexual Networks}

IN HASP Round IV Surveillance, less than 5 percent of MSWs, HSWs, and MSWs reported injecting drug use (NACP, 2012). In Round II of the surveillance, 22 percent of PWID paid for sex with female sex workers in the last six months and 13 percent paid for sex with males or hijra sex workers. Approximately 7 percent of FSWs, 6.4 percent of MSWs and 4.6 percent of HSW respectively reported having sex with a PWID in the past six months (UNGASS 2010). Injecting drug use by sex workers was recorded at 9.1 percent among FSW, 4.2 percent among MSW and 6.3 percent among HSW.

Similarly, among a sample of more than 396 MSM in Karachi and nearby rural areas of Sangar and Larkana in Sindh, 86 respondents (21.7 percent) reported injection drug use and 25 reported contacts with sex workers. Among HIV-positive MSM, the proportion reporting injection drug use was 17.4 percent; approximately 36 percent reported contacts with commercial sex workers (Khanani et al. 2010). However, the high prevalence of circumcision in Pakistan (> 95 percent) and the improving rate of condom use among sex workers (condom use during last sexual encounter with a commercial client is estimated at 43 percent for FSWs and 33.1 percent for MSWs and HSWs) is likely to reduce the risk of heterosexual transmission between these groups, despite some minimal overlap of sexual networks among PWID and CSWs.

The maintenance of a very low rate of HIV infection among FSW in Pakistan, sustained over many years of high prevalence among PWID, suggests that it is unlikely to change despite recent reports of a slight increase of HIV prevalence. Continued surveillance of FSWs is arguably called for, but prevention resources should be focused on the regular female partners of HIV-infected PWID-women likely to be at substantial risk. Treatment for HIV+ PWID, as demonstrated in the 
recent HPTN 052 trial, which showed a 96 percent efficacy rate in reducing transmission in HIV discordant couples, should arguably be the "bridging" population priority in Pakistan. Overall, the sexual networks of People who inject drugs overlap only modestly with the sexual networks of HSWs or MSM.

Data on clients of HSWs are even more limited. A recent cross-sectional study from Karachi $(n=200)$ among clients of hijra sex workers reported very low rates of condom use (42.4 percent) during last sexual encounters with HSWs (Siddiqui et al. 2011).

\section{Special Populations}

There are concerns about HIV risk among special populations, however quantitative data on these populations is insufficient to determine their overall contribution to the HIV epidemic in Pakistan. These include:

\section{Prisoners}

There are approximately 76 prisons in Pakistan holding 96,000 prisoners. Additionally, there are four female prisons in Pakistan. A substantial proportion of inmates is incarcerated for drugrelated crimes. An anonymous, unlinked volunteer sample of 4,897 prison inmates in Sindh reported HIV among 49 participants (1 percent) (Safdar, Mehmood, and Abbas 2009). Similarly, another study among a random sample of prison inmates in Karachi reported HIV rates of 2 percent (95 percent $\mathrm{Cl}, 0 .-3.4$ ) (Kazi et al. 2010). Condom availability is low. Prison inmates also suffer reportedly high rates of TB as well as Hepatitis B and C infections. Some pilot programs provide antiretroviral therapy for prison inmates, such as those run by the Pakistan Institute of Medical Sciences, are promising but need to be scaled up.

\section{Truckers}

A study $(n=400)$ conducted in 2004 reported HIV rates of 1 percent among truckers and their assistants (Bokhari et al. 2007). Several other qualitative studies have been conducted but highquality data on whether they act as a bridging population has not been forthcoming.

\section{Blood donors}

There are reasons to be concerned about the quality of the blood supply in Pakistan, since the majority of blood transfusions happen in the unregulated private sector. There are approximately 1.5 million units of blood being transfused in Pakistan annually (NACP 2011), with 50 percent conducted through the private sector. Furthermore, there is a large pool of professional donors. Only approximately 87 percent of the blood is screened for HIV in Pakistan (UNGASS 2010). A highly publicized outbreak of HIV in Jalal Pur Jattan, Gujrat in 2008 appears to be a case of iatrogenic transmission and was fortunately a rare event in Pakistan (NACP 2008b). Molecular 
epidemiology data in such iatrogenic outbreaks are useful but are not available for the Jalal Pur Jattan outbreak. In a recent study among 7,148 blood donors from KPK and the FATA areas, 224 had anti-HCV antibodies according to immunochromotography tests (Khan et al. 2011). Similarly, the rates of Hepatitis B in Pakistan are reportedly high (Khan et al. 2011). Despite these high rates of Hepatitis B and Hepatitis C, overall low prevalence rates of HIV in blood donors are reported. In a recently reported surveillance study in Khyber Pakhtunkhwa, only 0.45 percent or 28/62251 samples were HIV-positive (Safi 2011). Since the portion of the population that is injecting constitutes a very small fraction of the total at-risk population, it is less likely that rates of HIV will mirror the rising rates of Hepatitis B or Hepatitis C in Pakistan in the blood supply, although the high rate of unregulated transfusions in the private sector will continue to pose ongoing challenges.

\section{Returning Migrants}

The net migration rate from Pakistan is currently estimated at $-3.3 / 1000$ inhabitants. The rapid migration from Pakistan to the Gulf has increased remittances, but it has also created problems, including long-term separation of migrant laborers from their families, and increased risk exposure to HIV infection while overseas. We could not find estimates of prevalence rates of HIV among migrants to determine their contribution to the overall HIV epidemic, which remains largely confined to high-risk groups. In contrast to the substantial minority of PWID and HSWs receiving antiretroviral therapy, the majority of persons receiving antiretroviral therapy $(\approx 70$ percent) are migrants returning from periods of employment and residence in the Middle East and their seropositive wives. Returning migrants constitute a substantial proportion of those receiving ART in provinces such as KPK. This high proportion in treatment likely reflects their differential access to ARV treatment services, compared to other high-risk groups.

\section{Refugees}

Approximately 1.9 million Afghanistan refugees reside in Pakistan (Khanani et al. 2010). A convenience sample of 556 refugees reported rates of HIV of around 6 percent, with HCV rates as high as 36.8 percent and Hepatitis B surface antigen positivity of 9.17 percent (Khanani et al. 2010). Drug use was highly prevalent in this sample.

\section{HCV and STIs}

Almost 10 million people are living in Pakistan with HCV infection. A nationwide study of over 3,351 serum samples found the genotype $3 a$, which is most associated with injection drug use, present in 49.05 percent of these (Idrees and Riazuddin 2008). A serum test of 1,364 patients from the only public hospital in Lahore to practice HCV testing also found genotype $3 a$ to be the dominant type, comprising 55.09 percent of the total (Ahmad et al. 2010). 
In regard to HCV prevalence among PWID, a venue-based study in Lahore and Quetta found very high prevalence rates of 92.9 percent and 75 percent, respectively (Kuo et al. 2006). A respondent-driven sampling study from Rawalpindi and Abbottabad reported surprisingly low levels of HCV prevalence among PWID, at 17.3 percent in the first city and 8 percent in the second (Hawkes et al. 2008).

With other STIs, syphilis levels in the general population remain low. A Punjab retrospective study found a prevalence of 3.2 percent among 32,420 clinically healthy men (Hyder et al. 2010). Screening of blood donors in Khyber Pakhtunkhwa province found 2.6 percent prevalence (Safi 2011). However, syphilis among the hijra population is an area of concern. In Karachi, a study with limited methods reported a syphilis prevalence rate among hijras of 37 percent (Baqi et al. 1999).

\section{Urban and Rural Trends}

According to the Federal Bureau of Statistics, in 2005 Pakistan had an estimated population of 162,151,000. About 52.4 percent of this population is in Punjab, 23 percent in Sindh, 15.8 percent in Khyber Pakhtunkhwa, and 4.96 percent in Balochistan. Of the total estimated population, 32.5 percent live in urban areas, whereas 67.5 percent live in rural areas. National surveys and surveillance among HRGs have focused on major cities spanning all four provinces and little data is available regarding HRGs and seroprevalence among rural populations. Through consultation with the National HIV/AIDS Control Program, the 2007 HASP report derived a rural factor to estimate the size of HRGs in rural populations through an educated guess. For PWID and HSWs these urban-to-rural estimates were 53,546 to 37,566 and 25,308 to 17,569 respectively.

Estimated Number of HIV+ per High-Risk Group by City

Using the city-level prevalence rates from the HIV/AIDS Surveillance Program Round III and the city-level estimates of high risks from the NACP, the table below illustrates the estimated number of HIV-positive individuals per high-risk group per city. These estimates allow for programs that are targeted at the city level and again depict a manageable number to target with available resources. 
Table 5: Estimated Number of HIV+ per High-Risk Group by City

\begin{tabular}{|c|c|c|c|c|c|c|c|c|c|}
\hline 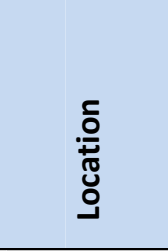 & 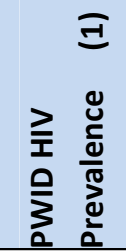 & 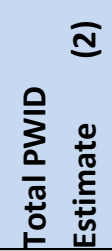 & 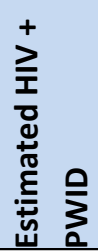 & 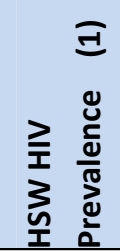 & 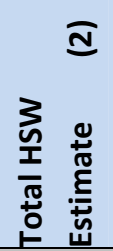 & 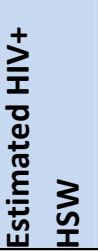 & 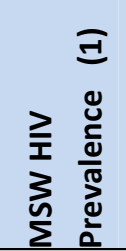 & 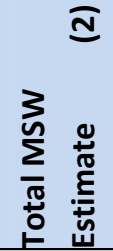 & 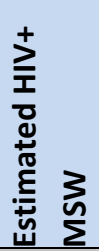 \\
\hline \multicolumn{10}{|l|}{ PUNJAB } \\
\hline Faisalabad & $12.30 \%$ & 5,444 & 670 & $2.50 \%$ & 2,102 & 53 & $0.00 \%$ & 2,992 & 0 \\
\hline Sargodha & $22.80 \%$ & 2,263 & 516 & $* 6.35 \%$ & 874 & 55 & $* 0.75 \%$ & 1,244 & 9 \\
\hline Lahore & $14.50 \%$ & 9,115 & 1,322 & $2.49 \%$ & 3,520 & 88 & $0.99 \%$ & 5,010 & 50 \\
\hline \multicolumn{10}{|l|}{ SINDH } \\
\hline Karachi & $23.10 \%$ & 12,469 & 2,880 & $3.60 \%$ & 7,525 & 271 & $3.05 \%$ & 6,984 & 213 \\
\hline Larkana & $28.50 \%$ & 1,248 & 356 & $27.64 \%$ & 753 & 208 & $0.50 \%$ & 699 & 3 \\
\hline Hyderabad & $30.50 \%$ & 2,472 & 754 & $0.00 \%$ & 1,492 & 0 & $0.00 \%$ & 1,385 & 0 \\
\hline \multicolumn{10}{|c|}{ BALOCHISTAN } \\
\hline DG Khan & $18.60 \%$ & 22 & 4 & $* 6.35 \%$ & 26 & 2 & $* 0.75 \%$ & 248 & 2 \\
\hline \multicolumn{10}{|l|}{ KPK } \\
\hline Peshawar & $12.80 \%$ & 146 & 19 & $1.24 \%$ & 90 & 1 & $0.00 \%$ & 849 & 0 \\
\hline
\end{tabular}

* National estimate per high risk-group from NACP 2008, due to no city-level data being available Sources: 1. NACP III 2008; 2. HASP II 2007.

\section{Provincial Trends in HIV}

Provincial-level data were unavailable with most studies and national surveillance focused on city data. Regional trends by province are best represented in the estimated size of the high-risk groups, as illustrated in Table 6, as well as by risk behaviors for PWID and PWID seroprevalence.

Table 6: Estimated Size of High-Risk Groups by Province, 2007

\begin{tabular}{|l|l|l|l|l|l|l|}
\hline & Punjab & Sindh & $\begin{array}{l}\text { Khyber } \\
\text { Pakhtunkhwa }\end{array}$ & Balochistan & Islamabad & Total \\
\hline PWID & 63,578 & 25,380 & 527 & 414 & 1,215 & 91,114 \\
\hline FSW & 92,803 & 31,137 & 6,743 & 3,780 & 1,837 & 136,300 \\
\hline MSW & 34,945 & 14,215 & 5,580 & 7,228 & 668 & 62,636 \\
\hline HSW & 24,553 & 15,316 & 593 & 1,946 & 469 & 42,877 \\
\hline
\end{tabular}

Source: HASP II 2007.

Despite the lack of provincial data, the second generation HASP from 2008 surveyed eight cities across all four provinces. The report did not include FSWs, due to the minimal amounts testing positive in prior surveillance. While no MSM data were recorded, the MSW reports that reached 
adequate sample size were not statistically significant. Three cities using network sampling had statistically significant HIV prevalence among HSWs. These were Lahore (2.5 percent, 95 percent $\mathrm{Cl}$ : 0.3-4.7), Faisalabad (2.5 percent, 95 percent $\mathrm{Cl}$ : 0.3-4.7), and Karachi (3.6 percent, 95 percent $\mathrm{Cl}$ : 1.2-6.1). Although it failed to meet adequate sample size by one participant, the reported HIV prevalence among HSW in Larkana was considerably high (27.6 percent, 95 percent $\mathrm{Cl}$ : 21.4-33.9).

Prevalence estimates from HASP 2008 show an overall HIV prevalence of 21 percent among PWID across eight cities (Table 7). However, Sindh province has reported the highest prevalence of HIV among PWID, with 30.5 percent in Hyderabad, 28.5 percent in Larkana, and 23.1 percent in Karachi.

Table 7: HIV Prevalence among PWID (95 percent CI) by City, 2008

\begin{tabular}{|l|l|l|}
\hline Province & City & HIV Prevalence \\
\hline \multirow{4}{*}{ Punjab } & Faisalabad & $12.3 \%$ \\
\cline { 2 - 3 } & Sargodha & $22.8 \%$ \\
\cline { 2 - 3 } & Lahore & $14.5 \%$ \\
\hline \multirow{3}{*}{ Sindh } & Karachi & $23.1 \%$ \\
\cline { 2 - 3 } & Larkana & $28.5 \%$ \\
\cline { 2 - 3 } & Hyderabad & $30.5 \%$ \\
\hline Balochistan & DG Khan & $18.6 \%$ \\
\hline \multirow{2}{*}{$\begin{array}{l}\text { Khyber } \\
\text { Pakhtunkhwa }\end{array}$} & Peshawar & $12.8 \%$ \\
\hline
\end{tabular}

Source: NACP 2008a.

To explore trends in Pakistan, national surveillance data for the same cities were compared from 2005 and 2008 (Table 8).

Table 8: Comparison of HIV Prevalence among PWID by City, 2005 and 2008

\begin{tabular}{|l|l|l|}
\hline City & $\mathbf{2 0 0 5}$ & $\mathbf{2 0 0 8}$ \\
\hline Lahore & $3.75(2.2-6.0)$ & $14.46(11.0-17.9)$ \\
\hline Faisalabad & $13.25(10.2-17.0)$ & $12.25(9.0-15.5)$ \\
\hline Peshawar & $.35(0-1.9)$ & $12.99(8.6-17.2)$ \\
\hline Hyderabad & $25.38(21.2-30.0)$ & $30.4(26.0-35.0)$ \\
\hline Country & $10.78(9.6-12.1)$ & $20.82(19.4-22.3)$ \\
\hline
\end{tabular}

Sources: NACP 2005; NACP 2008a. 
Table 8 shows HIV prevalence among PWID in Lahore, Peshawar and at the country level as being significantly increased in statistical terms from 2005 to 2008. Although Faisalabad and Hyderabad did not change significantly, the level of HIV prevalence remained high.

In regard to drug use and risk behavior in the scope of provincial trends, poly drug use was highly common throughout the eight cities surveyed in the HASP 2008. The anti-histamine Avil was reported to be the drug of choice among the Punjab cities of Lahore, Faisalabad and Sargodha, with over 91.7 percent injecting the drug at least once over the past month. Interestingly, these Punjab cities reported the lowest proportion of PWID sharing syringes/needles on last injection. By contrast, Sindh province-represented by Karachi, Larkana, and Hyderabad-reported higher levels of needle sharing, and these are cities with the highest burden of HIV among PWID.

\section{Figure 9: Proportion of PWID Sharing Syringes/Needles on Last Injection by City, 2008}

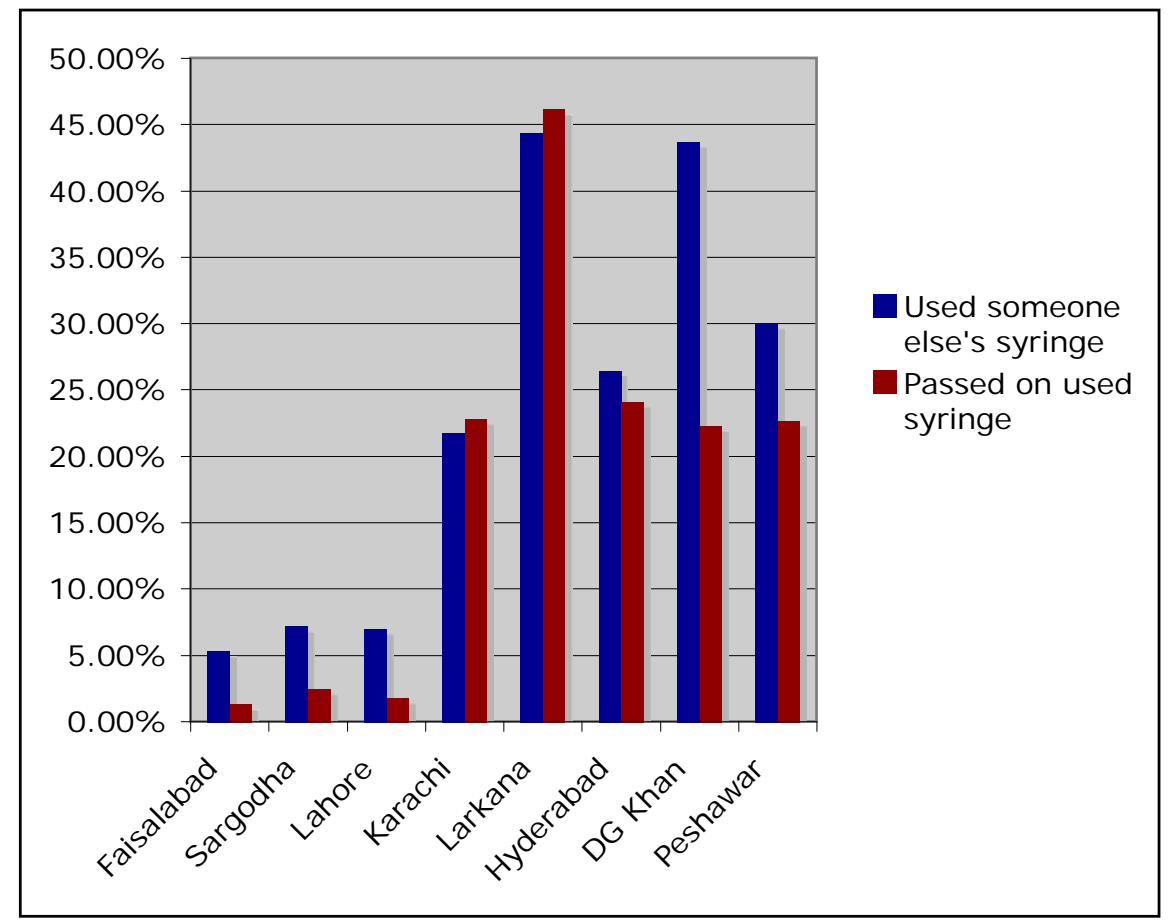

Source: NACP 2008a.

\section{Provincial Review - Sindh}

Sindh province is the second-largest province in Pakistan, with an estimated population of $35,257,564$. About 59.9 percent of this population is between the ages of 15 and 64 . The urbanto-rural proportion is 48.8 percent and 51.2 percent, respectively. Sindh province has the secondlargest estimate of populations considered high-risk. PWID users are estimated at 17,878 in urban areas and 7,502 in rural areas, for a total of 25,380. FSWs are estimated at 21,933 in urban areas 
and 9,204 in rural areas, for an estimated total of 31,137. MSW are estimated at 10,013 in urban areas and 4,202 in rural areas, for a total of 14,215. HSW are estimated at 10,789 in urban areas and 4,527 in rural areas, for an estimated total of 15,316.

Table 9: Estimated High-Risk Groups in Sindh, 2007

\begin{tabular}{|l|l|l|l|}
\hline & Urban & Rural & Total \\
\hline PWID & 17,877 & 7,502 & 25,380 \\
\hline FSW & 21,933 & 9,204 & 31,137 \\
\hline MSW & 10,013 & 4,202 & 14,215 \\
\hline HSW & 10,789 & 4,527 & 15,316 \\
\hline
\end{tabular}

Source: HASP II 2007.

Of the eight cities across Pakistan surveyed in the 2008 HASP, the highest HIV prevalence among PWID users was found in three Sindh cities: 30.5 percent (95 percent $\mathrm{Cl}$ : 26.40-35.0) in Hyderabad, 28.5 percent (95 percent $\mathrm{Cl}: 24.0-33.0$ ) in Larkana, and 23.1 percent ( 95 percent $\mathrm{Cl}$ : 19.0-27.2) in Karachi. These very high prevalence rates are cause for concern. Despite sample size of 200 being reached, the 0.5 percent (95 percent $\mathrm{Cl}$ : $-0.5-1.48$ ) HIV prevalence among MSW in Larkana is not considered statistically significant, given the confidence intervals.

Table 10: HIV Population Prevalence in Sindh, 2008

\begin{tabular}{|l|l|l|l|}
\hline & Karachi & Hyderabad & Larkana \\
\hline PWID & $23.10 \%$ & $30.50 \%$ & $28.50 \%$ \\
\hline FSW & - & - & - \\
\hline MSW & $3.05 \%$ & 0 & $0.50 \% *$ \\
\hline HSW & $3.60 \%$ & 0 & $27.64 \%$ \\
\hline
\end{tabular}

$*=$ Confidence Interval overlaps 0.0 percent

Source: HASP III 2008.

FSW were not included in the HASP from 2008, given the minimal seroprevalence from previous surveys. Few data are available regarding seroprevalence of MSM. However, estimated rates in Sindh province include 18.0 percent in Larkana, 12.41 percent in Karachi, and 2.78 percent in Sanger (Khanani 2010).

The Sindh province health department established the Sindh AIDS Control Program in 1994-95. The Control Program maintains HIV treatment and care centers at two public hospitals, located in Karachi and Larkana, and two private hospitals, both in Karachi. It tallies 46 STI clinics and 21 VCT centers and it has supported the creation of a 70-member network of HIV/AIDS NGOs/CBOs to 
promote community participation (Sindh AIDS Control Program 2011). There is no record of needle and syringe programs (NSP) in Sindh.

The Sindh province health department uses a passive surveillance system for HIV/AIDS. Passive systems assume interaction with healthcare settings that facilitate HIV testing, an issue for hidden or marginalized populations such as PWID, HSW, and MSW. Active surveillance is conducted nationally through HASP and IBBS. Active sites are cities, and do not provide rural data. Gaps in data include rural data, methods of sampling high-risk populations and linkages in the continuum of care. Quality epidemic modeling and molecular epidemiology analysis are unable to be conducted.

Records provided by the Sindh province health department (Sindh AIDS Control Program 2011) illustrated that 11,624 HIV tests were conducted in 2010, the lowest total number since 2007. Of these, 633 tested HIV-positive, which accounts for the second highest amount since 2005. In essence, fewer people are being tested and more are testing positive, which can serve as an indicator of more targeted testing taking place in Sindh.

\section{Provincial Review - Punjab}

Punjab is by far the most populated of the four provinces, accounting for an estimated 52.4 percent of the total population in 2009. There are more people living in rural Punjab than in both the rural and urban areas of Sindh province combined. Furthermore, unlike Sindh, Punjab's population is overwhelmingly rural, comprising 68.7 percent of the total.

In regard to HIV risk groups, Punjab outweighs the combined total estimates from all other provinces in each of the four main groups: PWID, FSW, MSW and HSW.

Table 11: Estimated High-Risk Groups in Punjab, 2007

\begin{tabular}{|l|l|l|l|}
\hline & Urban & Rural & Total \\
\hline PWID & 33,857 & 29,721 & 63,578 \\
\hline FSW & 49,417 & 43,386 & 92,803 \\
\hline MSW & 18,610 & 16,335 & 34,945 \\
\hline HSW & 13,074 & 11,479 & 24,553 \\
\hline
\end{tabular}

Source: HASP II 2007.

Of the eight cities across Pakistan surveyed in the 2008 HASP, three Punjab cities found highly concentrated prevalence rates among PWID, including 14.5 percent (95 percent $\mathrm{Cl}$ : 11.0-17.9) in Lahore, 12.3 percent (95 percent $\mathrm{Cl}$ : $9.0-15.5$ ) in Faisalabad, and 22.8 percent (95 percent $\mathrm{Cl}$ : 
18.7-26.9) in Sargodha. These very high prevalence rates are cause for concern. Despite a sample size of 200 being reached, the 1 percent (95 percent $\mathrm{Cl}$ : -0.4-2.4) HIV prevalence among MSW in Lahore is not considered statistically significant, given the confidence intervals.

Table 12: HIV Population Prevalence in Punjab, 2008

\begin{tabular}{|l|l|l|l|}
\hline & Lahore & Faisalabad & Sargodha \\
\hline PWID & $14.50 \%$ & $12.30 \%$ & $22.80 \%$ \\
\hline FSW & - & - & - \\
\hline MSW & $1 \%^{*}$ & 0 & - \\
\hline HSW & $2.50 \%$ & $2.50 \%$ & - \\
\hline
\end{tabular}

* = Confidence interval overlaps 0.0 percent

Source: HASP III 2008.

\section{Limitations}

Our review was limited by the paucity of data on potentially high-risk populations, such as men who have sex with men outside the context of sex work. There was limited data on various aspects of the programmatic response especially at the provincial levels, which precluded a much more granular analysis of relative provincial burdens, costs and efficiency and effectiveness of the HIV response. The published studies on HIV among various high-risk populations were too heterogeneous, precluding any meaningful meta-analyses as planned (Tables 2-4). We were limited by the paucity of data in carrying out further modeling projections of the HIV epidemic. While our review was comprehensive and examined all data sources that were available in the published literature and provided to us by country partners, any review is limited by the potential for some publication bias. Despite these limitations, there was sufficient data to inform an evidence-based response outlined below.

\section{Research Gaps in Surveillance and Programmatic Response}

Our review identified that there are several gaps in the surveillance of HIV, particularly among high-risk groups and their clients or partners. Firstly, there is very little data on the prevalence of HIV among men who have sex with men outside the context of sex work. The absence of studies among these potentially high-risk groups should not be construed as evidence of absence of HIV among men who have sex with men in Pakistan until the appropriately designed studies are conducted. Most of those we identified were cross-sectional studies with no prospective studies.

Our conservative estimates for the estimated number of high-risk groups ( PWID, FSWs, HSWs,) infected with HIV shown in the Table above are substantially lower than other projections about the number of HIV-infected persons in Pakistan, which reach roughly 96,000 by other accounts. 
Although we did not have access to the underlying assumptions for these national projections, we view them with caution. Most of the data on HIV in Pakistan we reviewed was from urban and suburban epidemics among high-risk groups. There was very little data on rural HIV. Hence national projections of the number of HIV-positive individuals in Pakistan may need to be revised to accurately capture the rural factor (and downgraded accordingly), as several countries have had to do over the last few years. 


\section{Epidemiology - Summary of Key Findings}

Pakistan has a highly concentrated epidemic of HIV-1, with evidence of high rates of infection among most at risk populations for many years but very low general population rates of HIV, < 1/1000. Despite substantial provincial variation and heterogeneity, a concentrated HIV epidemic has been consistently reported among injecting drug users, male sex workers, hijra sex workers and female sex workers in the major urban cities in multiple studies although the estimates of HIV are moderately imprecise (Strength of Evidence-Moderate).

We found evidence of self-sustaining transmission among core populations of PWID, HSWs and MSW in the major urban cities. This was seen in multiple studies, was reasonably consistent but downgraded for moderate imprecision (Strength of Evidence Moderate).

Although FSWs are at risk for STIs, they have consistently reported low prevalence rates of HIV because heterosexual transmission of HIV is likely terminal in the setting of majority of males being circumcised in Pakistan. (Strength of Evidence-Moderate).

There was minimal overlap of the sexual networks among these core populations suggesting that a single strategy or venue is unlikely to suffice for most at risk populations. (Strength of Evidence - Low).

Pakistan is unlikely to experience a generalized epidemic. Our analysis of sexual behaviors among PWID and hijras, triangulated with the level of the epidemic, provide sufficient information to corroborate the hypothesis/finding that Pakistan is unlikely to experience a generalized epidemic. The Asian epidemic model of transmission of HIV from at-risk populations of PWID and sex workers to the general population via bridging populations has been suggested as a possible scenario Pakistan's future. However, after two decades, the epidemic remains highly concentrated among high-risk groups in Pakistan. Support for this assertion is based on triangulating data from several sources and analyzing multiple facets of Pakistan's HIV epidemic.

As previously mentioned, two large HIV screenings of pregnant women found no cases of the virus, despite high rates among PWID and in some samples of MSWs. Second, multiple studies and the National HIV/AIDS Surveillance Round I show extremely low rates of HIV among FSWs, suggesting sustained low rates of HIV in the client base of these women. 
Lastly, the high rate of male circumcision (95 percent) in the country almost certainly has played a role in reducing the risk of heterosexual transmission of HIV. In 2008, a metaanalysis of three Randomized Control Studies totaling 11,050 African men showed that male circumcision reduces the risk of female-to-male transmission by 56 percent (Mills et al. 2008). However, evidence of a protective effect of circumcision in male-to-male transmission is inconsistent (Templeton 2010) and a meta-analysis examining direct reduced risk of circumcision in male-to-female transmission showed non-significant results (Weiss, Hankins and Dickson 2009). Thus, while the data above do suggest a selfsustaining mode of transmission in the most at risk populations, the lack of substantial overlap of sexual networks along with the high rates of circumcision in Pakistan suggest that onward transmission to the general population or overlapping sexual networks are likely to be minimal, except in the case of wives and partners of PWID and HSWs. These data provide some reassurance with respect to the threat of a generalized epidemic (Strength of Evidence-Moderate).

* Given the high rates of HIV among PWID, who are overwhelmingly male in the studies, and the suggestive emerging epidemic among hijra sex workers, the wives of HIV-positive PWID, HSW and their clients, and the wives of MSM, these Pakistani populations are arguably of greater concern when it comes to the secondary spread of HIV than the general population. This is encouraging from a prevention standpoint, because these relatively small and focused populations can be targeted for effective prevention strategies, including treatment for HIV-infected partners. As an important step, already infected female partners of high-risk men should be a prevention priority for reproductive care services in general, but with a primary focus on PMTCT services. Broad PMTCT services were attempted in Pakistan, but due to the very low rates in general population samples of pregnant women were not cost-effective. Using men at risk to identify female partners at risk would be much more cost-effective and require many fewer resources. Risk assessment of women presenting for antenatal care may be less productive in this context, since many women may know little about, or be unwilling to disclose, their husband's actual HIV risk profile.

* Population-Attributable Risk Analysis (PAR): Using available epidemiologic surveillance data on at-risk populations, size estimates for these populations from the HIV/AIDS Surveillance Program (HASP) Round IV, and an estimated general population prevalence of 0.0004 percent among reproductive-aged adults we conducted a populationattributable risk analysis for PWID, FSWs, MSWs, HSWs, and MSM who were not sex workers (Table 15). In all, some 99 percent of cumulative HIV infections in Pakistan have been among these five high-risk groups, despite their accounting for well under 2 percent 
of all adults. PWID accounted for the largest share of infections for any one group, some 36.4 percent overall. Female, male, and transgender sex workers accounted for 24 percent, 12 percent, and 17.5 percent respectively, a cumulative PAR of 53.5 percent of all infections occurring among sex workers.

\section{Table 13: Population-Attributable Risk Analysis}

\begin{tabular}{|l|l|l|l|l|l|}
\hline Risk group & HIV Prevalence, \% * & $\begin{array}{c}\text { Prevalence Risk } \\
\text { Ratio § }\end{array}$ & $\begin{array}{c}\text { Attributable } \\
\text { Risk, \% }\end{array}$ & $\begin{array}{c}\text { Prevalence of } \\
\text { Exposure in } \\
\text { Population, per } \\
1000 \text { adult males** }\end{array}$ & $\begin{array}{c}\text { Population- } \\
\text { Attributable } \\
\text { Risk, \% }\end{array}$ \\
\hline PWID & 27.2 & 68 & 98.5 & 3.7 & 36.4 \\
\hline FSW & 0.6 & 1.5 & 33.3 & 7.2 & 24 \\
\hline MSW & 1.6 & 4 & 75 & 1.6 & 12 \\
\hline HSW & 5.2 & 13 & 92.3 & 1.9 & 17.5 \\
\hline MSM & 10.99 & 27.3 & 96.3 & $1.0^{++}$ & 9.6 \\
\hline
\end{tabular}

* NACP 2012; ** NACP 2012.

$\S$ PRR estimated based on baseline risk of HIV in Pakistan $=0.0004$ percent from antenatal surveillance study among pregnant women (NACP 2012).

I Khanani et al 2010, a cross-sectional RDS sample of MSM in Karachi.

++ Data on prevalence of male-to-male sex behavior unavailable from HASP and extrapolated from a data synthesis of Middle East and North Africa at the very conservative estimate of 1/1000, Mumtaz 2010.

Note: Attributable risk and population-attributable risk may sum up to $>100$ percent because of shared risk factors.

The epidemic of HIV in Pakistan is concentrated in the major urban cities as consistently seen in multiple studies of reasonable validity although the prevalence rates reported were somewhat imprecise due to sampling uncertainty. Data on rural transmission of HIV are markedly limited although with rapid urbanization of these major cities, and population mobility the boundaries between the urban, suburban and rural areas are increasingly getting blurred in Pakistan (Strength of Evidence - Moderate).

- Although high rates of Hepatitis B and Hepatitis C are reported in the blood supply, the overall contribution of this to the burden of the HIV epidemic in Pakistan remains unsubstantiated (Strength of Evidence - Low).

In conclusion, given the high rates of HIV among PWID, who are overwhelmingly male in the studies, and the suggestive emerging epidemic among hijra sex workers, the wives of HIV-positive 
PWID, HSW and their clients, and the wives of MSM, these Pakistani populations are the priority for HIV/STI prevention, treatment, care and support. Female sex workers remain a priority group given the slight increase of HIV prevalence rates documented in the 2011 IBBS (NACP 2012), and the large presence and diversification of typology coupled with heightened marginalization. 


\section{A Systems Response to HIV and AIDS in Pakistan}

As the epidemiology review presented here demonstrates, Pakistan has a concentrated epidemic with high HIV prevalence among quite specific groups at risk: PWID, hijra sex workers, and male sex workers in selected sites, mainly in urban areas. Female sex workers remain a priority group given the slight increase of HIV prevalence rates documented in the 2011 IBBS, and the large presence and diversification of typology coupled with heightened marginalization. While there are challenges involved in reaching these populations, not to mention providing services to them and generally engaging them in health care, the marked concentration of HIV in these few groups along with the overall very low rates in the general population could make for a potentially focused, cost-effective, and targeted response strategy.

Since the first outbreak in Sindh in 2003-04, national and international actors swiftly responded to evidence of the existence of a concentrated epidemic among PWID. HIV prevention interventions have been implemented for FSW and, to a lesser extent, for MSM and HSWs as well. By the mid-2000s, needle syringe exchange programs (NSEP) were being implemented in large cities and, with an annual budget of around US\$10 million through the "Enhanced AIDS Control Programme" focusing on PWID as well as sex work through World Bank, DFID and

government funding (Khan 2011). Harm and risk reduction measures, implemented through provision of "one-stop shop" services targeting key populations, namely PWID, FSWs, HSWs and MSWs, included NSEP, treatment of drug dependence, condoms, prevention and treatment of STI, primary health care including referral for Hepatitis and Tuberculosis (TB), prevention education through outreach, and peer and social support. VCT and referral to ART were part of the package.

\section{Insufficient Coverage, Intensity and Scale Up of Effective Prevention Interventions}

Despite adequate prioritization of the response and resources, PWID face several barriers in terms of access to both prevention and treatment services. HIV prevalence and related behavior indicators suggest lags in implementation. Evidence has demonstrated that saturation with clean needles through NSEP is one of the key elements required to curtail new HIV infections among PWID. Drug treatment, and particularly OST with methadone, buprenorphine, or suboxone, is an evidence-based approach to prevention for HIV-negative PWID, and a critical component of medically assisted therapy (MAT) supporting ART adherence for HIV-positive PWID (Altice et al. 2010). VCT-the much-needed link in the continuum of services to ensure awareness of HIV status and access to treatment and care-is part of the package of services, along with access to high-quality Highly Active Antiretroviral Therapy (HAART), both as treatment and prevention.

The number of NSEP sites/10,000 PWID is only 0.1 , and only an estimated 22.7 percent of PWID 
are accessing services (Bergenstrom et al. 2010). There is limited information about the key indicators to measure performance and quality of services provided to PWID. However, the data indicates that the implementation of the comprehensive package of interventions in Pakistan remains of limited coverage, too limited to cause behavior change and impact the HIV epidemic trajectory. The requirement that HIV-positive PWID remain drug-free remains a significant barrier for linking HIV-positive PWID to services.

Less than 1 percent of HIV-infected PWID are receiving antiretroviral treatment in Pakistan (Strathdee et al. 2010). Although these data should not be generalized, anecdotal reports from the Pakistan Institute of Medical Sciences also report a decline in the number of PWID on treatment in the last year, since the NGO linking PWID to treatment has been unable to provide that service. There is no evidence suggesting that the number of HIV-positive PWID has declined. The recent report that the Global Fund for AIDS, TB and Malaria (GFATM) Round IX would be awarding some US\$43 million over five years to the NACP and Nai Zindagi Trust to scale up comprehensive HIV prevention and harm-reduction services in 24 districts in Punjab and Sindh provinces may reduce a number of these barriers to services (Qamar 2011).

OST is in a pilot phase. Following discussions with health, narcotic control and drug regulatory authorities, OST will be piloted in the city of Rawalpindi, Punjab. A pilot oral substitution program for approximately 300 PWID will begin in prisons close to Islamabad. Resources have also been allocated from the Global Fund for the planned and progressive scale-up based on the results of the pilot. As of early 2012, however, changes in the ranks of government decision makers have delayed necessary action on this. Only licensed psychiatrists can currently provide OST in Pakistan, a potentially severe restriction on access. Buprenorphine, the more effective but costlier therapy, cannot be imported into Pakistan (US\$4/day) while methadone (US\$0.90/day) is cheaper and will be imported. Nevertheless, the adoption of OST is a critical and strategic opportunity to ensure that drug treatment services are linked to both VCT and to ART. Stabilized drug users on OST have much better treatment outcomes and referral linkages will also potentially improve access and adherence to ART.

Outreach is critical and yet NGOs have a limited number of outreach workers, relying instead on fixed and costly drop-in centers (Khan 2011). In a context of implementing programs for hard-toreach populations, significant variations in the implementation capacities of NGOs and community-based organizations to engage with at-risk populations determine the ability to implement scaled-up programs. NGOs, such as Nai Zindagi, Pakistan Society, Al-Najat and others have played and will likely continue to play key roles in outreach and service provision, given their grassroots connectivity with marginalized PWIDs. 
For the hijra community, equivalent NGOs do not exist at the same level. But unlike PWID, the hijra communities themselves have organized and articulated social structures and community leaders. The key need for hijra is thus for the health authorities and HIV programs to reach out to indigenous hijra community structures and engage them in the HIV response. The longstanding and traditional social capital of this community is an untapped resource. Social capital appears to be markedly lower for sex workers and their clients, as both the number and capacity of the organizations working with sex workers is limited. However, NGO capacity is likely to expand with the Global Fund R-9 regional grant award for MSM and hijra. Currently, there is not sufficient evidence to assess the relative uptake and provision of VCT throughout the country's health system or by NGOs by specific risk and vulnerable populations. It appears that access and linkages to care for risk populations through VCT is still very limited.

\section{ART Unmet Need}

New data on eligibility demonstrates a high level of unmet need in Pakistan, particularly in priority areas, as among HIV-positive pregnant women (Table 4). Although anecdotal, the quality of ART appears to be quite reasonable at the Pakistan Institute of Medical Sciences in Islamabad. There is a national policy of initiating ART at CD4 levels below 350, which is reassuring and consistent with other evidence-based guidelines, and high-quality ART is available at the major medical centers in key cities such as Islamabad, Lahore, Karachi and Peshawar.

The estimated number of adults (15+) in need of ART in 2010 was 20,000 (14,000-47,000). Given that there are approximately 1,900 people currently on ART treatment, the unmet need for eligible treatment is over 90 percent. This percentage may be underestimated, given the wide confidence interval for the estimated number of adults in need of treatment.

Table 14: Pakistan ART Eligibility Estimates 2010

\begin{tabular}{|c|c|c|c|c|c|c|}
\hline \multirow{2}{*}{ Year } & \multicolumn{2}{|c|}{$\begin{array}{l}\text { Total pop. }(15+) \text { in need of } \\
\text { ART }\end{array}$} & \multicolumn{2}{|c|}{ Children (0-14) in need of ART } & \multicolumn{2}{|c|}{ Mothers needing РМТCT } \\
\hline & Estimate & $\begin{array}{l}\text { Low - High } \\
\text { estimate }\end{array}$ & Estimate & $\begin{array}{l}\text { Low - High } \\
\text { estimate }\end{array}$ & Estimate & $\begin{array}{l}\text { Low - High } \\
\text { estimate }\end{array}$ \\
\hline 2005 & 3,100 & {$[1,800-6,100]$} & $<500$ & {$[<500-<1,000]$} & $<1,000$ & {$[<500-1,600]$} \\
\hline 2006 & 3,800 & {$[2,300-7,900]$} & $<500$ & {$[<500-<1,000]$} & $<1,000$ & {$[<1,000-1,900]$} \\
\hline 2007 & 4,800 & {$[2,900-10,000]$} & $<1,000$ & {$[<500-1,500]$} & 1,000 & {$[<1,000-2,300]$} \\
\hline 2008 & 6,100 & {$[3,800-13,000]$} & $<1,000$ & {$[<1,000-1,800]$} & 1,200 & {$[<1,000-2,900]$} \\
\hline 2009 & $16,000 *$ & {$[11,000-37,000]$} & $<1,000$ & {$[<1,000-2,100]$} & 1,400 & {$[<1,000-3,500]$} \\
\hline 2010 & $20,000 *$ & {$[14,000-47,000]$} & 1,400 & {$[<1,000-3,400]$} & 1,600 & {$[<1,000-4,200]$} \\
\hline
\end{tabular}

* ART eligibility criteria for adults set to CD4 count $<=350$ from 2009 onwards Source: UNAIDS/WHO Working Group. 
The population of persons on ARVs is heavily overrepresented by returning migrant workers and their families, and is heavily underrepresented by the two populations with the highest measured HIV infection rates-PWID and hijra, as well as the other two at-risk populations. Data from 2010 reported that 80 percent of those receiving ART among 567 registered cases at the Provincial AIDS program were migrants or their spouses (deportees 53 percent, their spouses 23 percent and children 9 percent) (UNGASS 2010).

According to the UNAIDS/World Bank Working Group, the number of mothers needing PMTCT in 2010 was 1,600 (<1,000 - 4,200). Other data from the UNGASS 2010 Pakistan Country Report shows that only 25 out of 5,663 HIV-positive pregnant mothers ( 0.44 percent) receive antiretroviral therapy and 28.9 percent of children born to HIV-positive mothers are themselves HIV-infected. This major gap on access to treatment for HIV pregnant mothers was reinstated in the UNGASS 2012 Report.

\section{Estimation of High-Risk Groups Requiring Therapy}

Data illustrate those most in need-PWID, hijra and sex workers living with HIV—still have limited access. Despite substantive efforts to reach PWID with harm reduction and prevention packages, including VCT, it is estimated that fewer than 1 percent of PWID in need of ARVs were on treatment before 2010 (Strathdee et al. 2010). These very low levels of treatment for at-risk populations are increasingly being understood to have critical prevention as well as treatment impact, since untreated HIV leads to greater infectiveness (Cohen et al. 2011). Furthermore, the UNODC/UNAIDS/WHO Global recommendations stress the importance of a combination of nine core interventions, including NSEP, OST and ART, to reduce HIV transmission among PWID.

Using the data on population size and estimated HIV prevalence among high-risk groups, the table below demonstrates that the number of HIV-positive individuals within high-risk groups is a manageable proportion. 
Table 15: Estimated Number of High-Risk Groups Requiring Therapy

\begin{tabular}{|c|c|c|c|c|}
\hline Risk group & $\begin{array}{l}\text { Estimated } \\
\text { Population } \\
\text { Size } \\
(1)\end{array}$ & $\begin{array}{l}\text { HIV } \\
\text { Prevalence } \\
{[95 \% \mathrm{CI}]} \\
(2)\end{array}$ & $\begin{array}{l}\text { National } \\
\text { estimates } \\
\text { of HIV- } \\
\text { infected } \\
\end{array}$ & $\begin{array}{l}\text { Assuming } \\
33 \% \text { on } \\
\text { treatment }\end{array}$ \\
\hline PWID & 91,114 & $\begin{array}{l}20.8 \% \\
(19.4-22.3 \%)\end{array}$ & 18,951 & 6,254 \\
\hline FSW & 136,300 & $\begin{array}{l}0.19 \% \\
(0.07-.45 \%)\end{array}$ & 259 & 86 \\
\hline MSW & 62,636 & $\begin{array}{l}0.75 \% \\
(0.3-1.5 \%)\end{array}$ & 497 & 164 \\
\hline HSW & 42,877 & $\begin{array}{l}6.3 \% \\
(5.0-7.7 \%)\end{array}$ & 2,702 & 892 \\
\hline
\end{tabular}

Sources: 1. HASP 2007; 2. NACP 2008.

Assuming that only one-third of these require therapy, the number of HRGs requiring HAART in Pakistan is estimated to be a manageable number, within the reach of available resources. However, despite the consistent high prevalence of HIV, several barriers prevent PWID from easily accessing both prevention and treatment services. Although national policy has been revised on this, many health care professionals continue to require that HIV-positive PWID be drug free in order to receive ART, which is a significant barrier for linking HIV-positive PWID to treatment services.

\section{Emerging Challenges to the AIDS Response}

Overall, Pakistan has made strides over the last decade in its AIDS response, with active surveillance, considerable research, both governmental and non-governmental prevention and care activities, and treatment since 2005-06. The gains made to date are threatened by internal and external factors.

Pakistan has seen a marked decline in external funding and decreasing donor focus on HIVspecific support in 2010-11, which resulted in the disruption of services for PWID and other risk populations. Global Fund Round IX funding in the amount of US\$43 million has been awarded to Pakistan to provide comprehensive harm-reduction services to injecting drug users in 24 districts of the two largest provinces-Punjab and Sindh-as well as community- and home-based care for people living with HIV across all provinces over a span of five years (Global Fund for AIDS, Tuberculosis and Malaria 2012). 


\section{Provincial Deregulation and Implications for HIV Response}

A second concern for Pakistan is the recent decision to devolve health sector functions to the provincial level in 2010 (Moriani 2012). A series of rapid changes have been promulgated in Pakistan through the $18^{\text {th }}$ Amendment, with power sharing between the federal Government and the four major provinces. Several legislative lists that allowed for both the federal Government and the provincial governments to legislate have been abolished. Under the $18^{\text {th }}$ Amendment, the right to education has been cited as a fundamental human right. The dissolution of the Ministry of Population and the dissolution of the Ministry of Health, which began in June 2011, pose challenges and opportunities. It is unclear which national agency will henceforth monitor public health more broadly. More than half of healthcare in Pakistan is delivered in the private sector, however its role in response to the HIV epidemic has not been clearly articulated. The resurgence of other diseases such as polio in Pakistan raises questions of whether provincial deregulation without an adequate national response will be sufficient to control communicable diseases that do not respect state or national boundaries. Thus provincial authorities will have to synergize and prioritize their health problems, including that of HIV. This process may impact HIV programs through the potential loss of central-level surveillance, planning, programming, procurement, normative guidance, and resource allocation. Reassuringly, however, the Provincial AIDS Control Programs in the Departments of Health have subsequently assumed greater responsibility for some of these functions, while the role and scope of the National AIDS Control Program is being redefined to follow-up on international legal agreements, such as that of the Global Fund, as well as redefine reporting functions.

The shrinking of HIV resources coupled with other competing health priorities in Pakistan drive a renewed focus on investing in an evidence-proven combination of HIV prevention, treatment care and support programs targeting PWID, hijras, male sex workers as well as female sex workers and their sexual partners. Fiscal constraints have generated pressure to provide clear evidence of impact of interventions and deliver better value for money. Selecting the optimal mix of interventions to address the epidemic dynamics is the first step towards achieving an effective and efficient response.

Effective and efficient implementation of an optimal mix of interventions at required coverage and uncompromised quality is urgently needed to prevent the epidemic's further spread and optimize scarce resource utilization. Given the diversity within the country and differences between the epidemic profile of each province, it will be important to select a mix of interventions and service-delivery models tailored to the local epidemic dynamics for each province. While there will be short-term gaps in the programmatic and policy response to HIV, nevertheless reflecting the continuing commitment of provincial governments, there is also a window of opportunity in which to reduce dependence on external funding, as well as greater 
prioritization, given that local funds would have to be increasingly deployed, and a potential for greater longer-term integration into health services. In 2012, five-year provincial AIDS strategies were developed and local funding increased in the Punjab and Sindh provinces from around 20 percent to 40 percent of overall needs, particularly for HIV-related harm, risk reduction and ART. 


\section{Key Policy Recommendations}

Our analysis indicates the following recommendations:

Key Policy Recommendations

- Select the optimal mix of interventions tailored to the local epidemic dynamics and sociobehavior characteristics of key populations at risk and their sexual partners, aligned with the provincial epidemic profile and dynamics.

- Develop service delivery models adapted to the local context, which include: increased outreach and engagement with PWID, hijra communities, and male and female sex workers, their clients and sexual partners;

- Markedly expand HIV voluntary testing and counseling (VCT) services for those at most risk, in settings and contexts where PWID, HSWs and MSWs will use the services and receive quality counseling;

- Markedly improve linkages to care from outreach and from VCT to HIV treatment with ARVs

- Markedly improve linkages for HIV+ and HIV- PWID into evidence-based drug treatment services, including methadone maintenance therapy (MMT), wherever available

- Expand targeted HIV testing, linkages to care, and ARV for the female partners (wives) of PWID and MSWs-a population of women at substantial risk for HIV infection and whose access to care and services is likely limited;

- Renew vigorous national commitment to blood and blood product safety, and to universal precautions in both public and private sector health care services;

- Invest resources, including increased provincial public resources, to ensure full-scale implementation of HIV prevention, treatment and care programs;

- Undertake systematic efficiency and effectiveness analysis of interventions and implementation practices to inform selection of the most effective interventions and innovative service delivery models informed by the local context.

\section{An Integrated Model for Improved HIV Services Delivery in Pakistan}

These results can be achieved only when service delivery models circumvent the implementation challenges that preclude the targeted scale-up of a combination of HIV-effective interventions. There is a need to develop, implement and evaluate service delivery models tailored to the local epidemic dynamics and the characteristics of the targeted population and their sexual partners. 
To date, successful replications of multidimensional prevention interventions with integrated links to treatment across the country depend on program delivery (Padian et al. 2011).

The service delivery models will likely have in common key components, which we have suggested in the Integrated HIV Service Delivery Model in Fig. 9, which represents the optimal mix of interventions. Prevention services, largely delivered through outreach, such as needle and syringe exchange for PWID and street outreach for hijra and MSWs are the entry point for these populations into a continuum of care. A key next step is establishing improved linkages between outreach services and HIV testing and counseling. These linkages may be improved through a variety of approaches, including mobile testing services, point-of-care rapid screening, and VCT provided at NSEP sites and at hijra- and MSW-friendly clinic sites. VCT is the key step for moving forward in this continuum.

Figure 10: Integrated Model for HIV Services Delivery

\begin{tabular}{|c|c|c|c|c|c|}
\hline & $\begin{array}{c}\text { Prevention } \\
\text { Outreach } \\
\text { BCC }\end{array}$ & Links to VC & VCT & $\begin{array}{l}\text { Links from } \\
\text { VCT to care }\end{array}$ & $\begin{array}{r}\text { ARV } \\
\text { Treatment }\end{array}$ \\
\hline Population & $\begin{array}{l}\text { IDU } \\
\text { HSW } \\
\text { MSW } \\
\text { FSW }\end{array}$ & $\begin{array}{l}\text { IDU } \\
\text { HSW } \\
\text { MSW } \\
\text { FSW }\end{array}$ & $\begin{array}{l}\text { Specific for } \\
\text { MSM/hijra } \\
\text { IDU } \\
\text { friendly } \\
\text { clinic }\end{array}$ & $\begin{array}{l}\text { IDU } \\
\text { HSW } \\
\text { MSW } \\
\text { FSW }\end{array}$ & \\
\hline Activity & $\begin{array}{c}\text { NSEP/MMT } \\
\text { Street } \\
\text { Outreach } \\
\text { Hijra } \\
\text { Outreach }\end{array}$ & VCT & $\begin{array}{l}\text { Mobile } \\
\text { testing } \\
\text { VSEP with } \\
\text { testing } \\
\text { STI clinics }\end{array}$ & $\mathrm{MMT}$ & $\begin{array}{r}\text { CD4 Viral } \\
\text { load staging } \\
\text { TB Care } \\
\text { PMTCT } \\
\text { Treatment \& } \\
\text { Hospitalization }\end{array}$ \\
\hline Implementers & $\begin{array}{c}\text { NGOs } \\
\text { Hijra } \\
\text { Community }\end{array}$ & $\begin{array}{c}\text { NGOs } \\
\text { Hijra } \\
\text { Community } \\
\text { Prov HA }\end{array}$ & $\begin{array}{c}\text { MOPH } \\
\text { NACP } \\
\text { Private } \\
\text { Prov HA }\end{array}$ & $\begin{array}{c}\text { NGOs } \\
\text { Peers } \\
\text { MOPH } \\
\text { Prov HA }\end{array}$ & $\begin{array}{c}\text { NACP } \\
\text { MOPH } \\
\text { Prov HA }\end{array}$ \\
\hline
\end{tabular}

BCC: Behavior Change Communication; MMT: Methadone Maintenance Therapy; NSEP: Needle and Syringe Exchange Program; Prov HA: Provincial Health Authority 


\section{Outreach and Engagement for those at risk: PWID, HSW, MSW}

Outreach and engagement, including behavioral change communications (BCC) for PWID, have been largely conducted in Pakistan in partnership with NGOs. This key role is likely to continue, as NGOs have the grassroots connectivity, trust, and expertise to access hidden and marginalized PWID. For the hijra community, equivalent NGOs do not exist at the same level. But unlike PWID, the hijra communities themselves have highly organized and articulated social structures and community leaders. The key outreach need for hijra is thus for the health authorities and HIV programs to reach out to indigenous hijra community structures and engage them in HIV response efforts. The longstanding and traditional social capital of the hijra community is an untapped resource. For MSW and their clients, where social capital appears markedly lower, NGO capacity is likely to expand with the Global Fund non-CCM award to the Naz Foundation.

\section{HIV Testing and Counseling}

The current situation with respect to HIV testing is a serious challenge to HIV prevention and control in Pakistan. Since the withdrawal of World Bank support for VCT for drug users in Punjab, testing access appears to have all but ceased. HIV VCT is the key gateway to knowing one's status, to HIV treatment options, and to prevention services. It is the cornerstone of AIDS care. Providing VCT is also clearly a public function, not simply the role of an NGO, and must be made available to those at risk and to their wives and other partners.

Three potential models for VCT services for most-at-risk populations (MARPs) have been described. These include:

\section{Full Integration}

Full integration, where services for MARPs are integrated into mainstream HIV programs, may be optimal in some settings. Full integration will likely require active efforts to reduce stigma and discrimination in service delivery. Healthcare worker training and sensitization for working with MARPs will be essential in settings where integrated models are considered. All levels of staff need this training-it is often at the level of security guards, intake clerks and other non-medical staff that PWID, HSWs and MSWs are actively discouraged from seeking care.

Levels of stigma may also vary among at-risk groups in integrated HIV testing settings. A man with HIV seeking ARV treatment may have no reason to disclose past or current sex work-there is little benefit to disclosure and considerable potential harm. PWID, however, may be unable to hide their substance use history from providers and may need management of both ARVs and substance use; moreover, the provision of quality clinical care may be dependent on disclosure.

\section{Stand-Alone Services}

Stand-alone HIV service delivery for MARPS is currently a topic of considerable debate. Stand- 
alone services may protect MARPS from some forms of discrimination but may also increase stigma. Peer-educator social workers are an integral part of the provision of care to ensure respectful and rights-based services. However, these peer services could not include ARV management. Striking a balance between stand-alone services as protective and the potential for ongoing discrimination will be a challenge wherever this model is implemented.

\section{Hybrid Models}

Models are likely to vary markedly by the type of services provided, most notably for prevention, VCT, and ARV care. Community-based groups have records of success in providing outreach and bringing PWID, in particular, into VCT. Harm-reduction networks are good examples, where users and their communities provide essential outreach and key services, including NSP. But these same groups may be unable to provide ARV therapy or other clinical services. Hybrid models, where prevention is done through community groups linked to integrated but MARPs-friendly treatment programs may be an optimal approach for Pakistan, where both sets of services exist or could be established, and where public programs are open to collaborating with communitybased service providers.

\section{Linkages to HIV Care}

Despite some 90,000 to 110,000 persons thought to be living with HIV in 2011 , and despite having a free and good-quality national ARV treatment program, Pakistan has relatively few people currently accessing the public ARV program, amounting to fewer than 2,000 persons in 2011. A further challenge is that the population of persons on ARVs is heavily overrepresented by returning migrant workers and their families and heavily underrepresented by the two populations with the highest measured HIV infection rates: PWID and hijra. At least some of this "disconnect" is due to weak linkages to care programs for these populations. Passive referral for treatment is unlikely to be effective for marginalized populations. PWID and hijra will likely need skilled peer advocates to negotiate treatment access. In addition, health care worker sensitization and training will likely be required to improve the quality of services for these populations and ensure their participation, adherence, and engagement in prevention services. Sensitization training may also be required for security and police forces to insure that PWID are not harassed when seeking health care services. Effective referral mechanisms need to be included as part of the comprehensive package of interventions, as well as ensuring that budget and staff are properly allocated.

\section{Linkages to Drug Treatment}

The scientific literature provides abundant evidence that drug treatment, and particularly opioid substitution therapy (OST) with methadone, buprenorphine, or suboxone, is an evidence-based approach to HIV prevention for HIV-negative PWID, and a critical component in supporting ARV adherence for HIV-positive PWID. Since Pakistan, in collaboration with UNODC, is now piloting 
methadone maintenance therapy (MMT), this is an important strategic opportunity to ensure that drug treatment services are linked to both HIV VCT and to ARV access programs. Stabilized drug users on MMT have much better treatment outcomes than those not on MMT, and so these linkages will also potentially improve ARV program strength.

\section{Expanded Targeting and HIV Testing, Linkages to Care, and ARV for Women at Risk}

Most PWID in Pakistan are young men, and virtually all MSWs are young men. A significant proportion of both groups report being married. The wives of PWID, in particular, are likely to be the largest group of women in Pakistan at risk for HIV infection, but are a hidden and little studied group. Since Pakistan has such low rates of HIV infection among the general population of women of reproductive age and has made the sound decision not to pursue universal testing strategies for pregnant women, the targeting of VCT to women at real risk seems highly appropriate. This will likely require working through NGO and peer networks of men at risk to encourage couples counseling and couples-based VCT for drug users, but could yield benefits both for women at risk and for PMTCT in the case of those women already living with HIV.

\section{Blood Products Safety and Universal Precautions}

Since the blood supply comes largely from the private sector and is unregulated in Pakistan, especially in the rural areas, ensuring a safe and adequate blood supply is challenging. The standardized testing of blood should be made routine, not only for HIV but for Hepatitis B and C and syphilis as well. Efforts must be made to increase awareness about voluntary donations in order to curb the population's dependence on professional donors. 


\section{Conclusion}

Pakistan, like many countries with highly concentrated epidemics among subgroups of the population, can make great strides by focusing and targeting their response through integrated HIV service models that engage the most-at-risk populations. This targeted approach could increase the overall cost effectiveness of the response and ensure a return on investments. While surveillance must be maintained in other populations to detect potential wider spread, Pakistan has the potential to control further HIV spread now and to provide services for those living with HIV, requiring relatively modest investment and a re-focusing of resources on those in need. The window of opportunity to make these changes remains open, but timely and targeted responses are urgently called for.

Effective and efficient response will require selecting the optimal mix of HIV prevention interventions, primarily for PWID and their sexual partners, male sex workers and hijras, as well as female sex workers and their sexual partners, aligned with the epidemic profile and dynamics at provincial level. Particular attention and analysis shall be focused not only on "which intervention to invest on and implement" but also on "how to implement a high-quality continuum of services" that ensure uptake and service utilization by the concerned populations. Thus, locally adapted service delivery models shall be designed, implemented and evaluated to ensure that key populations at risk are reached with services at the required coverage and intensity to cause change and impact the HIV epidemic trajectory. These services need to embed effective links and referral to VCT and ART treatment for key populations at risk, and that will mean expanding access in Pakistan to people who use drugs as well as to male and hijra sex workers.

Responding to such highly concentrated but low-general-population-prevalence HIV epidemics will become increasingly challenging as donor resources decline in settings such as Pakistan. Systematic studies of intervention effectiveness and implementation aiming to render services effective and efficient need to inform resource allocation and operational adjustments. Focused and evidence-based responses could have potent impacts on reducing HIV transmission among those at risk, and ensuring services for those who need them. 


\section{References}

Abbas, S. 2010. Special Surveillance Round for Female Sex Workers (FSW). National AIDS Control Program.

Abbasi, S. et al. 2009. "A serological study of hepatitis $C$ and human immunodeficiency virus in a cohort of intravenous drug users in Quetta, Balochistan." JPMI 23 (1): 3-6.

Achakzai, M., M. Kassi, \& P.M. Kasi. 2007. "Seroprevalences and co-infections of HIV, Hepatitis C virus and Hepatitis B virus in injecting drug users in Quetta, Pakistan." Tropical doctor 37 (1): 43-45.

Afridi, N.K., S. Khan, \& S. Fatima. 2010. "Factors affecting accessibility and acceptability of voluntary counseling and testing among high-risk groups (HRG) for human immunodeficiency virus (HIV) in NWFP Pakistan." The Journal of the Pakistan Medical Association 60 (4): 265269.

Ahmad, W., B. Ijaz, F.T. Javed, S. Jahan, I. Shahid, F.M. Khan, \& S. Hassan. 2010. "HCV genotype distribution and possible transmission risks in Lahore, Pakistan." World Journal of Gastroenterology 16 (34): 4321-4328.

Altaf, A., S. Abbas, \& H.A. Zaheer. 2008. "Men who have sex with men: new emerging threat of HIV/AIDS spread in Pakistan." The Journal of the Pakistan Medical Association 58 (8): 419420.

Altaf, A., N.Z. Janjua, S. Kristensen, N.A. Zaidi, A. Memon, E.W. Hook III, S.H. Vermund, \& S.A. Shah. 2009. "High-risk behaviours among juvenile prison inmates in Pakistan." Public Health 123 (7): 470-475.

Altaf, A., N. Saleem, S. Abbas, \& R. Muzaffar. 2009. "High prevalence of HIV infection among injection drug users in Hyderabad and Sukkur, Pakistan." The Journal of the Pakistan Medical Association 59 (3): 136-140.

Altaf, A., S.A. Shah, N.A. Zaidi, A. Memon, Nadeem-ur-Rehman \& N. Wray. 2007. "High-risk behaviors of injection drug users registered with harm reduction programme in Karachi, Pakistan." Harm Reduction Journal, 4: 7.

Ansari, J. "Outbreak investigation of HIV/AIDS in Jalalpur Jattan (JPJ), Pakistan 2008." Abstracts: E74.

Altaf, Arshad. 2009. HIV/AIDS Project: Review of Targeted Interventions. Sindh AIDS Control Program; Canada-Pakistan HIV/AIDS Surveillance Project. Karachi, Pakistan.

Asif, N., N. Khokhar, \& F. Ilahi. 2004. "Seroprevalence of HBV, HCV and HIV infection among voluntary non remunerated and replacement donors in Northern Pakistan." The Pakistan Journal of Medical Sciences 20 (1): 24-28.

Baqi, S., S.A. Shah, M.A. Baig, S.A. Mujeeb \& A. Memon. 1999. "Seroprevalence of HIV, HBV, and syphilis and associated risk behaviours in male transvestites (Hijras) in Karachi, Pakistan." International Journal of STD \& AIDS 10 (5): 300-304. 
Bergenstrom, A., N. Rehman, Z. Fazil, S. ul Hasan Qureshi, T. Zafar, \& M. Saleem. 2010. Pakistan Country Advocacy Brief: Injecting Drug Use and HIV. United Nations Regional Task Force on Injecting Drug Use and HIV/AIDS for Asia and the Pacific.

Beyrer, C., Z. Patel, J.A. Stachowiak, F.K. Tishkova, M.A. Stibich, L.M. Eyzaguirre, J.K. Carr, V. Mogilnii, A. Peryshkina, A. Latypov, \& S.A. Strathdee. 2009. "Characterization of the emerging HIV type 1 and HCV epidemics among injecting drug users in Dushanbe, Tajikistan." AIDS Research and Human Retroviruses 25 (9): 853-860.

Beyrer, C., M.H. Razak, K. Lisam, J. Chen, W. Lui, \& X.F. Yu. 2000. "Overland heroin trafficking routes and HIV-1 spread in south and south-east Asia." AIDS (London, England) 14(1): 75-83.

Bokhari, A., N.M. Nizamani, D.J. Jackson, N.E. Rehan, M. Rahman, R. Muzaffar, S. Mansoor, H. Raza, K. Qayum, P. Girault, E. Pisani, \& I. Thaver. 2007. "HIV risk in Karachi and Lahore, Pakistan: an emerging epidemic in injecting and commercial sex networks." International Journal of STD \& AIDS 18(7): 486-492.

Buse, K., N. Lalji, S.H. Mayhew, M. Imran, \& S.J. Hawkes. 2009. "Political feasibility of scaling-up five evidence-informed HIV interventions in Pakistan: a policy analysis." Sexually Transmitted Infections 85(Suppl. 2): ii37-42.

Carr, J.K., Y. Nadai, L. Eyzaguirre, M.D. Saad, M.M. Khakimov, S.K. Yakubov, D.L. Birx, R.R. Graham, N.D. Wolfe, K.C. Earhart \& J.L. Sanchez. 2005. "Outbreak of a West African recombinant of HIV-1 in Tashkent, Uzbekistan." Journal of Acquired Immune Deficiency Syndromes (1999) 39 (5): 570-575.

CIA June 14, 2011-last update. The World Factbook: Pakistan [Homepage of CIA], [Online]. Available: https://www.cia.gov/library/publications/the-world-factbook/geos/pk.html [2011, 6/16/2011].

Collumbien, M., J. Chow, A.A. Qureshi, A. Rabbani, \& S. Hawkes. 2008. "Multiple risks among male and transgender sex workers in Pakistan." Journal of LGBT Health Research 4(2-3): 7179.

Countdown to 2015. 2010. Pakistan: 2010 Report, Countdown to 2015. Geneva, Switzerland. de Lind van Wijngaarden, Jan, B. Rani, \& Q. Iqbal. 2010. Patterns, Meanings and Context of Adolescent Male to Male Sexual Experience in Pakistan: Results of a Qualitative Study in Five Cities aimed at Improving Sexual Health and Social Protection Programming. National AIDS Control Program; UNAIDS Pakistan; UNICEF Pakistan.

Emmanuel, F., S. Akhtar, A. Attarad, \& C. Kamran. 2004. "HIV risk behavior and practices among heroin addicts in Lahore, Pakistan." The Southeast Asian Journal of Tropical Medicine and Public Health 35(4): 940-948.

Emmanuel, F., C. Archibald, A. Razaque, \& P. Sandstrom. 2009. "Factors associated with an explosive HIV epidemic among injecting drug users in Sargodha, Pakistan." Journal of Acquired Immune Deficiency Syndromes (1999), 51(1): 85-90. 
Emmanuel, F., J. Blanchard, H.A. Zaheer, T. Reza, M. Holte-McKenzie, \& HASP team 2010. "The HIV/AIDS Surveillance Project mapping approach: an innovative approach for mapping and size estimation for groups at a higher risk of HIV in Pakistan." AIDS (London, England) 24(Suppl 2): S77-84.

Emmanuel, F. \& M. Fatima. 2008. "Coverage to curb the emerging HIV epidemic among injecting drug users in Pakistan: delivering prevention services where most needed." The International Journal on Drug Policy 19(Suppl 1): S59-64.

Ezard, N., E. Oppenheimer, A. Burton, M. Schilperoord, D. Macdonald, M. Adelekan, A. Sakarati, \& M. van Ommeren. 2011. "Six rapid assessments of alcohol and other substance use in populations displaced by conflict." Conflict and Health, 5(1): 1.

Faisel, A. \& J. Cleland. 2006. "Migrant men: a priority for HIV control in Pakistan?" Sexually Transmitted Infections 82(4): 307-310.

Family Health International (FHI) Pakistan 2006. BSS Round I - Long Distance Truck Drivers, FHI Pakistan.

Gill, R. \& D.E. Stewart. 2011. "Relevance of gender-sensitive policies and general health indicators to compare the status of South Asian women's health." Women's health issues: official publication of the Jacobs Institute of Women's Health. 21(1): 12-18.

Guyatt, G.H., A.D. Oxman, G.E. Vist, R. Kunz, Y. Falck-Ytter, P. Alonso-Coello, H.J. Schunemann, \& GRADE Working Group 2008. "GRADE: an emerging consensus on rating quality of evidence and strength of recommendations." BMJ (Clinical research ed.) 336(7650): 924-926.

Haque, N., T. Zafar, H. Brahmbhatt, G. Imam, S. ul Hassan, \& S.A. Strathdee. 2004. "High-risk sexual behaviours among drug users in Pakistan: implications for prevention of STDs and HIV/AIDS." International Journal of STD \& AIDS 15(9): 601-607.

Hawkes, S., M. Collumbien, N. Lalji, L. Platt, A. Andreasen, P. Vickerman, S. Mayhew, N. Jaafri, N. Rizvi, N. Rafiq, J. van Damn, J. Williams, \& R. Muzaffar. 2008. Sexually Transmitted Infections and HIV Among People with High Risk Behaviours: Results of Behavioural and Biological Surveys in Rawalpindi and Abbottabad, Pakistan. London School of Hygiene and Tropical Medicine.

Hawkes, S., M. Collumbien, L. Platt, N. Lalji, N. Rizvi, A. Andreasen, J. Chow, R. Muzaffar, H. urRehman, N. Siddiqui, S. Hasan, \& A. Bokhari. 2009. "HIV and other sexually transmitted infections among men, transgenders and women selling sex in two cities in Pakistan: a crosssectional prevalence survey." Sexually Transmitted Infections 85(Suppl 2): ii8-16.

HIV/AIDS Surveillance Project 2007. Estimates of High-risk Groups in Pakistan - 2006-07. National AIDS Control Program, Islamabad, Pakistan.

Qureshi, Huma. 2008. End Project Evaluation for GFATM Community Based Drop-in-Centre for Street Children Project, Implemented by PAVHNA in Karachi. Mustashaar, Social Development Advisors. Islamabad, Pakistan. 
Hyder, A.A., O.A. Khan, S.A. Shah, M.A. Memon, M.R. Khanani, \& S. Ali. 1999. "Sub-national response in HIV/AIDS: a case study in AIDS prevention and control from Sindh province, Pakistan." Public Health 113(1): 39-43.

Hyder, O., M. Ijaz, M.A. Arshad, \& T. Zahira. 2010. "Frequency of VDRL seropositivity among clinically healthy adult men from districts of Punjab province in Pakistan." Sexually Transmitted Infections 86(7): 513.

Idrees, M. \& S. Riazuddin. 2008. "Frequency distribution of hepatitis C virus genotypes in different geographical regions of Pakistan and their possible routes of transmission." BMC Infectious Diseases 8: 69.

Kazi, A.M., S.A. Shah, C.A. Jenkins, B.E. Shepherd, \& S.H. Vermund. 2010. "Risk factors and prevalence of tuberculosis, human immunodeficiency virus, syphilis, hepatitis B virus, and hepatitis C virus among prisoners in Pakistan." International Journal of Infectious Diseases : IJID : official publication of the International Society for Infectious Diseases14(Suppl 3): 60-6.

Khan, E., B.I. Memon, A. Ayaz, F. Malik, S.F. Shamin, F.S. Polani, \& A. Zafar. 2010. "Trend of syphilis in Pakistan, 1991-2008." Indian Journal of Microbiology 28(3): 263-264.

Khan, N.U., N.U. Ahmad, A. Iqbal, L.U. Rehman, I. Munir, M.U. Rehman, S. Khan, S. Ali, , L. Siddique \& Z.A. Swati. 2011. "Prevalence of active HCV infection among blood donors of Khyber Pakhtunkwa and FATA region of Pakistan and evaluation of the screening tests for Anti-HCV." 8: 154.

Khan, A.A., A.B. Awan, S.U. Qureshi, A. Razaque, \& S.T. Zafar. 2009. "Large sharing networks and unusual injection practices explain the rapid rise in HIV among IDUs in Sargodha, Pakistan." Harm Reduction Journal, 6: 13.

Khan, A.A. \& A. Khan. 2011. "Performance and coverage of HIV interventions for injection drug users: Insights from triangulation of programme, field and surveillance data from Pakistan." The International Journal on Drug Policy 22(3): 219-225.

Khan, A.A. \& A. Khan. 2010. "The HIV epidemic in Pakistan." JPMA The Journal of the Pakistan Medical Association 60(4): 300-307.

Khan, E., B.I. Memon, A. Ayaz, F. Malik, S.F. Shamim, F.S. Polani, \& A. Zafar. 2010. "Trend of syphilis in Pakistan, 1991-2008." Indian Journal of Medical Microbiology 28(3): 263-264.

Khan, F.H. 2009. "HIV and homosexuality in Pakistan." The Lancet Infectious Diseases 9(4): 204-5; author reply 205-6.

Khan, O.A. \& A.A. Hyder. 1998. "HIV/AIDS among men who have sex with men in Pakistan." Sexual Health Exchange 2(2):12-3, 15.

Khan, S., M.A. Rai, M.R. Khanani, M.N. Khan, \& S.H. Ali. 2006. "HIV-1 subtype A infection in a community of intravenous drug users in Pakistan." BMC Infectious Diseases 6: 164.

Khanani, M.R., M. Somani, S. Khan, S. Naseeb, \& , S.H. Ali. 2010. "Prevalence of single, double, and triple infections of HIV, HCV and HBV among the MSM community in Pakistan." The Journal of Infection 61(6): 507-509. 
Kuo, I., S. ul-Hasan, N. Galai, D.L. Thomas, T. Zafar, M.A. Ahmed \& S.A. Strathdee. 2006. "High HCV seroprevalence and HIV drug use risk behaviors among injection drug users in Pakistan." Harm Reduction Journal 3: 26.

Liu, J. \& C. Zhang. 2011. "Phylogeographic Analyses Reveal a Crucial Role of Xinjiang in HIV-1 CRF07_BC and HCV 3a Transmissions in Asia." PLOS ONE, 6(8): 1-12.

Mills, E., C. Cooper, A. Anema, \& G. Guyatt. 2008. "Male circumcision for the prevention of heterosexually acquired HIV infection: a meta-analysis of randomized trials involving 11,050 men." HIV medicine 9(6): 332-335.

Ministry of Finance. 2010. Pakistan Economic Survey 2009-10. Ministry of Finance, Islamabad, Pakistan.

Mir, A.M., A. Wajid, L. Reichenbach, M. Khan, \& I. Masood. 2010. "Herpes Simplex Virus-2 infection amongst urban male population in Pakistan." The Journal of the Pakistan Medical Association 60(11): 918-922.

Mumtaz, G., N. Hilmi, W. McFarland, R.L. Kaplan, F.A. Akala, I. Semini, G. Riedner, O. Tawil, D. Wilson, L.J. Abu-Raddad. 2010. Are HIV epidemics among men who have sex with men emerging in the Middle East and North Africa? A systematic review and data synthesis. PLoS Med 8(8): e1000444.

Nai Zindagi 2009. Rapid situational assessment of HIV prevalence and risk factors among people injecting drugs in four cities of the Punjab, Nai Zindagi, Islamabad, Pakistan.

Nai Zindagi 2008. The Hidden Truth: A study of HIV vulnerability, risk factors and prevalence among men injecting drugs and their wives. Nai Zindagi, Islamabad, Pakistan.

National AIDS Control Program. 2009. Limiting risk of HIV acquisition amongst adolescents most at risk in Pakistan: A proposed HIV prevention delivery model. National AIDS Control Program. Islamabad, Pakistan.

National AIDS Control Program. 2008a. HIV Second Generation Surveillance in Pakistan: National Report Round III. National AIDS Control Program. Islamabad, Pakistan.

National AIDS Control Program. 2008b. Report on Rapid Situation Analysis of the HIV Outbreak in Jalal Pur Jattan, Gujrat District. National AIDS Control Program. Islamabad, Pakistan.

National AIDS Control Program. 2007. HIV Second Generation Surveillance in Pakistan: National Report Round II. National AIDS Control Program. Islamabad, Pakistan.

National AIDS Control Program. 2005. HIV Second Generation Surveillance in Pakistan: National Report Round I. National AIDS Control Program. Islamabad, Pakistan.

National AIDS Control Program. 2012. HIV Second Generation Surveillance in Pakistan: National Report Round IV. 2012 National AIDS Control Program. Islamabad, Pakistan [forthcoming]. Pilon, R., R. Muzzaffar, M.A. Babar, S. Batool, D. Vallee, N.H. Saleem, F. Emmanuel, \& P. Sandstrom. 2010. "Characterizing HIV Transmission Patterns among Injecting Drug Users following an Outbreak in Sargodha, Pakistan" 
Platt, L., P. Vickerman, M. Collumbien, S. Hasan, N. Lalji, S. Mayhew, R. Muzaffar, A. Andreasen, \& S. Hawkes, 2009. "Prevalence of HIV, HCV and sexually transmitted infections among injecting drug users in Rawalpindi and Abbottabad, Pakistan: evidence for an emerging injection-related HIV epidemic." Sexually Transmitted Infections 85(Suppl 2): ii17-22.

Population Reference Bureau. 2012 World Population Data Sheet, [Online]. Available: http://www.prb.org/pdf12/2012-population-data-sheet eng.pdf [2012, 12/12/2012].

Qadir, M.I. \& S.A. Malik. 2011. "Genetic variation in the HR region of the env gene of HIV: A perspective for resistance to HIV fusion inhibitors." AIDS Research and Human Retroviruses 27(1): 57-63.

Qamar 2011. Minimizing transmission. The largest ever HIV project on HIV prevention. The Express Tribune. December 18, 2011.

Rai, M.A., V.R. Nerurkar, S. Khoja, S. Khan, R. Yanagihara, A. Rehman, S.U. Kazmi \& S.H. Ali. 2010. "Evidence for a 'Founder Effect' among HIV-infected injection drug users (IDUs) in Pakistan." BMC Infectious Diseases 10: 7.

Rai, M.A., A. Rajabali, M.N. Khan, M.A. Khan, \& S.H. Ali. 2009. "Educating the power: HIV/AIDS and parliamentarians of Pakistan." Health Research Policy and Systems/BioMed Central 7: 20.

Rajabali, A., S. Khan, H.J. Warraich, M.R. Khanani, \& S.H. Ali. 2008. "HIV and homosexuality in Pakistan." The Lancet Infectious Diseases 8(8): 511-515.

Rehan, N., I. Chaudhary, \& S.K. Shah. 2009. "Socio-sexual behaviour of hijras of Lahore." The Journal of the Pakistan Medical Association 59(6): 380-384.

Safdar, S., A. Mehmood, \& S.Q. Abbas. 2009. "Prevalence of HIV/AIDS among jail inmates in Sindh." The Journal of the Pakistan Medical Association 59(2): 111-112.

Safi, S.Z. 2011. Seroprevalence of hepatitis $C$ virus and human immunodeficiency virus in blood donors of North-Western Pakistan. 4th DICID.

Sanders-Buell, E., M.D. Saad, A.M. Abed, M. Bose, C.S. Todd, S.A. Strathdee, B.A. Botros, N. Safi, K.C. Earhart, P.T. Scott, N. Michael, \& F.E. McCutchan. 2007. "A nascent HIV type 1 epidemic among injecting drug users in Kabul, Afghanistan is dominated by complex AD recombinant strain, CRF35_AD." AIDS Research and Human Retroviruses 23(6): 834-839.

Shabbir, N., Q. Uzma, \& S. Abbass. 2010. "Assessing risk criteria and HIV prevalence in antenatal clinic clients from two urban tertiary hospitals in Pakistan." 7(Suppl 1): 148.

Shah, S. "Prevalence of syphilis among antenatal clinic attendees in Karachi: Imperative to begin universal screening in Pakistan."

Shah, S., H. Xing, A. Altaf, L. Lingjie, Y.Jia, S. Vermund \& Y. Shao. 2011. "Antiretroviral drug resistance mutations among treated and treatment naive patients in Pakistan: Diversity of HIV-1 pol gene in Pakistan." AIDS Research and Human Retroviruses.

Shah, S.A., A. Altaf, R. Khanani, \& S.H. Vermund. 2005. "Antiretroviral drugs obtained without prescription for treatment of HIV/AIDS in Pakistan: patient mismanagement as a serious 
threat for drug resistance." Journal of the College of Physicians and Surgeons--Pakistan: JCPSP 15(6): 378.

Shah, S.A., A. Altaf, S.A. Mujeeb, \& A. Memon. 2004. "An outbreak of HIV infection among injection drug users in a small town in Pakistan: potential for national implications." International Journal of STD \& AIDS 15(3): 209.

Shaw, S.Y., F. Emmanuel, A. Adrien, M. Holte-McKenzie, C.P. Archibald, P. Sandstrom, \& J.F. Blanchard. 2011. "The descriptive epidemiology of male sex workers in Pakistan: a biological and behavioural examination." Sexually Transmitted Infections 87(1): 73-80.

Siddiqui, M.H., J.A. Siddiqui \& I. Ahmed. 2009. "Demographic Profile and Clinical Features of Admitted HIV Patients in a Tertiary Care Teaching Hospital of Karachi, Pakistan." 25(5): 861864.

Siddiqui, AuR., H-Z. Qian, A.Altaf, H. Cassell, S.A.Shah, \& S.T.Vermund. 2011. “Condom use during commercial sex among clients of Hijra sex workers in Karachi, Pakistan (cross-sectional study)." BMJ Open 2: 1-5.

Sindh AIDS Control Program. 2011. Sindh Province Brief.

Strathdee, S.A., T.B. Hallett, N. Bobrova, T. Rhodes, R. Booth, R. Abdool, \& C.A. Hankins. 2010. "HIV and risk environment for injecting drug users: the past, present, and future." Lancet 376(9737): 268-284.

Strathdee, S.A., T. Zafar, H. Brahmbhatt, A. Baksh, \& S. ul Hassan. 2003. "Rise in needle sharing among injection drug users in Pakistan during the Afghanistan war." Drug and Alcohol Dependence 71(1): 17-24.

Templeton, D.J. 2010. "Male circumcision to reduce sexual transmission of HIV." Current Opinion in HIV and AIDS 5(4): 344-349.

World Bank. 2005. Improving Gender Outcomes: The Promise for Pakistan. The World Bank, Washington DC.

Towe, V.L., S. ul Hasan, S.T. Zafar, \& S.G. Sherman. 2009. "Street life and drug risk behaviors associated with exchanging sex among male street children in Lahore, Pakistan." The Journal of Adolescent Health: official publication of the Society for Adolescent Medicine 44(3): 222228.

U.S. Census Bureau. 2011. International Data Base - Pakistan [Homepage of U.S. Census Bureau], [Online]. Available: http://www.census.gov/ipc/www/idb/country.php [2011, 6/16/2011].

UNAIDS. 2010. Developing the evidence base for reinforcing HIV prevention, treatment, care and support among the flood-affected Populations in Pakistan, UNAIDS.

UNDP. 2010a. The Real Wealth of Nations: Pathways to Human Development. UNDP, NY.

UNDP. 2010b. Legal environments, human rights and HIV responses among men who have sex with men and transgender people in Asia and the Pacific. UNDP, Bangkok, Thailand.

UNGASS. 2010. Pakistan Country Report. UNGASS, NY.

UNODC. 2010. Annual Report: Promoting Health, Security and Justice. UNODC, Vienna, Austria. 
US Department of State. 2010. October 6, 2010 -last update, Background Note: Pakistan.

Available: http://www.state.gov/r/pa/ei/bgn/3453.htm [2011, 6/16/2011].

Weiss, H.A., C.A. Hankins, \& K. Dickson. 2009. "Male circumcision and risk of HIV infection in women: a systematic review and meta-analysis." The Lancet Infectious Diseases 9(11): 669677.

WHO \& Regional Office for the Eastern Mediterranean. 2007. Health Systems Profile: Pakistan, WHO, Geneva, Switzerland.

Zafar, T., H. Brahmbhatt, G. Imam, S. ul Hassan, \& S.A. Strathdee. 2003. "HIV knowledge and risk behaviors among Pakistani and Afghani drug users in Quetta, Pakistan.", Journal of Acquired Immune Deficiency Syndromes (1999) 32(4): 394-398. 


\section{Revitalizing the HIV Response in Pakistan: A systematic review and policy recommendations SYNTHESIS REPORT}

The Global HIV/AIDS Program

Health, Nutrition and Population

Human Development Network

1818 H Street, NW

Washington, DC 20433

Tel: +1 2024584946

Fax: +1 2025223234

www.worldbank.org/aids 